Nayara Salgado Carvalho

\title{
Eletrogastrografia multicanal em voluntários saudáveis e pacientes com diabetes mellitus tipo 1
}

Tese apresentada à Faculdade de Medicina da Universidade de São Paulo para obtenção do título de Doutor em Ciências

Programa de Ciências em Gastroenterologia

Orientador: Prof. Dr. Tomás Navarro Rodriguez

São Paulo

2020 
Dados Internacionais de Catalogação na Publicação (CIP)

Preparada pela Biblioteca da

Faculdade de Medicina da Universidade de São Paulo

Creprodução autorizada pelo autor

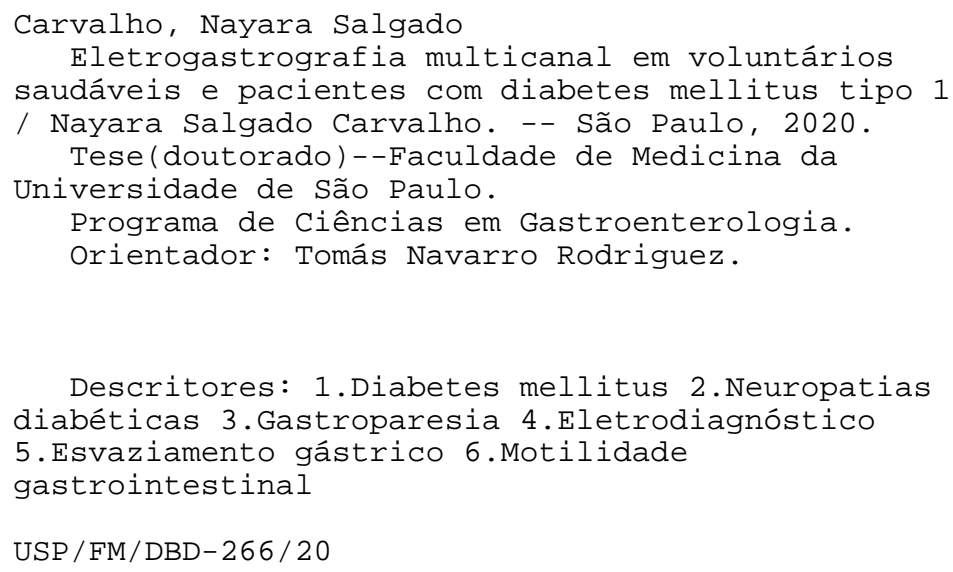




\section{DEDICATÓRIA}

A meus pais, Carlos Alberto (in memoriam) e Danuza, que nunca mediram esforços para a realização de meus sonhos. Minhas conquistas só foram possíveis graças ao amor, ao apoio e à dedicação que sempre tiveram por mim.

A minhas irmãs, Cynthia e Janaina, que, com amizade, carinho e incentivo, fortalecem minha caminhada em busca de meus ideais.

A meu namorado, Sergio, pelo companheirismo, pela compreensão e por sempre incentivar minhas conquistas. 


\section{AGRADECIMENTOS}

A Deus, primeiramente, por abençoar todos os dias de minha vida, iluminar meu caminho e me dar forças para seguir em frente.

Ao Prof. Dr. Tomás Navarro Rodriguez, pelos inúmeros ensinamentos, pela paciência, dedicação e confiança depositada em mim durante a orientação desta tese de doutorado. Meu reconhecimento pelo privilégio te ter sido orientada por profissional e pessoa exemplar.

Ao Dr. Paulo José Pereira Campos Carvalho, responsável pela idealização deste projeto, pelo incentivo diário, determinante para minha evolução profissional.

Ao Dr. Joffre Rezende Filho, pela motivação constante na realização deste trabalho e pela disponibilidade e generosidade em compartilhar comigo seus conhecimentos.

À Dra. Andrea Vieira, minha mestra, responsável por grande parte de minha formação como médica gastroenterologista, pela amizade, pela confiança e pelos conhecimentos transmitidos.

Ao Prof. Dr. Flair José Carrilho, professor titular da Disciplina de Gastroenterologia Clínica da Faculdade de Medicina da Universidade de São Paulo, pela oportunidade da realização deste trabalho.

Ao Dr Alex Jones Flores Cassenote, pelos ensinamentos e pela contribuição determinante na análise estatística deste trabalho. 
Ao Dr Flavio Steinwurz, pelos conhecimentos transmitidos, pela confiança, e pela motivação.

À Dra Marcia Queiroz, pelas orientações, pelo incentivo e pelo apoio imprescindíveis para a realização deste trabalho.

À colega Aline Vial Cobello, pela contribuição na seleção e captação dos pacientes participantes deste projeto.

Ao colega Diego Cardoso Baima, pela gentileza, apoio e por sempre demonstrar o caminho da tranquilidade.

A Vilma Libério, profissional da pós-graduação do programa de Ciências em Gastroenterologia, pela paciência, pelo auxílio e disponibilidade frente às minhas dúvidas e dificuldades.

Aos funcionários do Centro de Diagnóstico de Gastroenterologia, pela colaboração na realização dos exames de eletrogastrografia.

Aos voluntários e pacientes participantes, sem os quais a realização deste trabalho não teria sido possível. 


\section{NORMATIZAÇÃO ADOTADA}

Esta tese está de acordo com as seguinte normas, em vigor no momento desta publicação:

Referências: adaptado de International Committee of Medical Journals Editors (Vancouver).

Universidade de São Paulo. Faculdade de Medicina. Divisão de Biblioteca e Documentação. Guia de apresentação de dissertações, teses e monografias. Elaborado por Anneliese Carneiro da Cunha, Maria Julia de A. L. Freddi, Maria F. Crestana, Marinalva de Souza Aragão, Suely Campos Cardoso, Valéria Vilhena. 3a ed. São Paulo: Divisão de Biblioteca e Documentação; 2011.

Abreviaturas dos títulos dos periódicos de acordo com List of Journals Indexed in Index Medicus. 


\section{SUMÁRIO}

Lista de abreviaturas e siglas

Lista de tabelas

Lista de figuras

Resumo

Abstract

1 INTRODUÇÃO

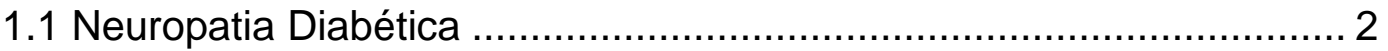

1.2 Gastroparesia Diabética ............................................................. 4

1.3 Atividade Mioelétrica Gástrica.................................................... 8

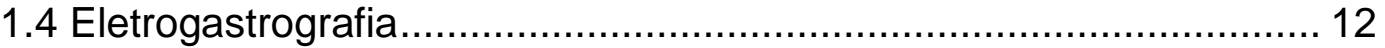

1.5 Distúrbio da Atividade Mioelétrica Gástrica ................................... 14

1.6 Relevância do Estudo ................................................................ 17

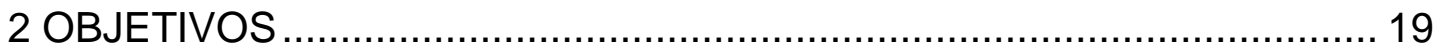

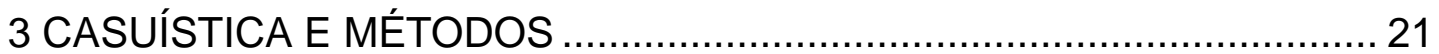

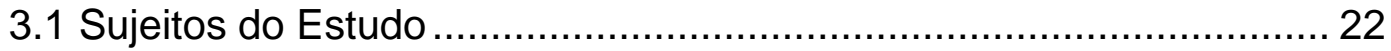

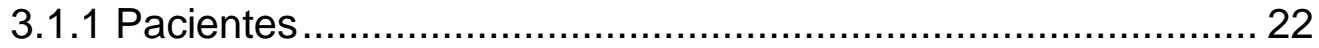

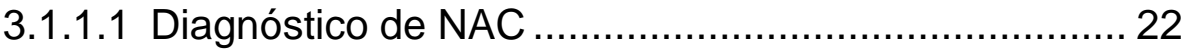

3.1.1.2 Esvaziamento gástrico por cintilografia ..................... 23

3.1.1.3 Questionário de Índice de Sintomas Cardinais de Gastroparesia ....................................................... 23

3.1.1.4 Separação dos pacientes em grupos .......................... 24

3.1.1.5 Critérios de inclusão dos pacientes............................ 24

3.1.1.6 Critérios de exclusão dos pacientes ............................ 24

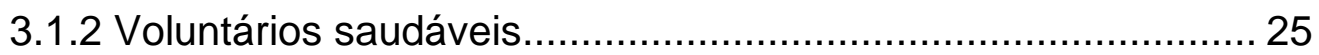

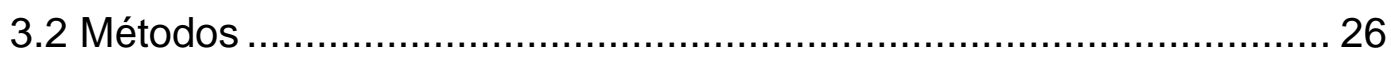

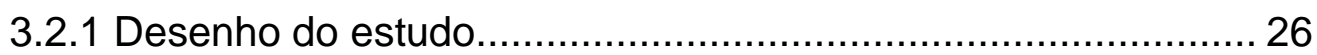

3.2.2 Realização da eletrogastrografia ......................................... 27

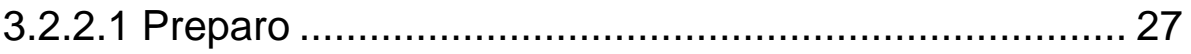

3.2.2.2 Posicionamento dos eletrodos .................................. 28 
3.2.2.3 Posição do indivíduo

3.2.2.4 Duração do registro................................................. 29

3.2.2.5 Análise do sinal da eletrogastrografia ........................ 30

3.2.2.6 Definição de eletrogastrografia normal ...................... 32

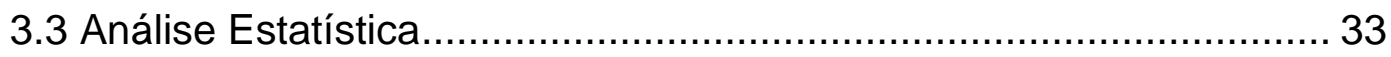

4 RESULTADOS

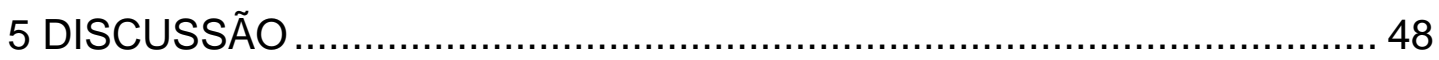

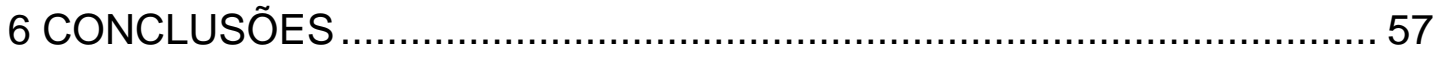

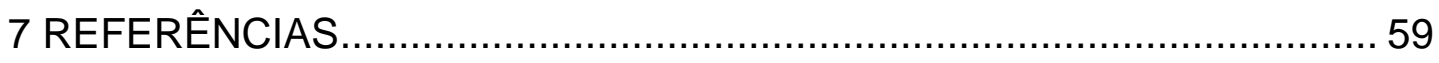

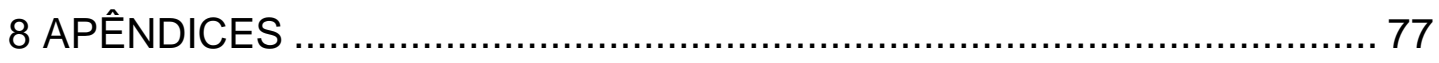

APÊNDICE A - Índice de Sintomas Cardinais de Gastroparesia

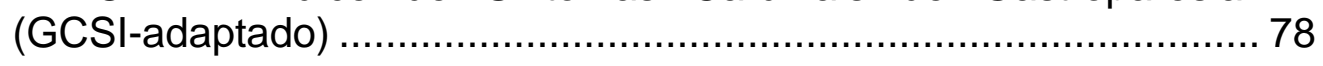

APÊNDICE B - Teste de normalidade incluindo média, desvio padrão e resultadodo teste de normalidade de todos os indivíduos incluídos no estudo.

APÊNDICE C - Padrões dos gráficos de evolução da frequência dominante (FD) em voluntários saudáveis (grupo controle)

APÊNDICE D - Padrões dos gráficos de evolução da frequência dominante (FD) em pacientes diabéticos sem neuropatia autonômica cardiovascular (grupo 1) .....

APÊNDICE E - Padrões dos gráficos de evolução da frequência dominante (FD) em pacientes diabéticos com neuropatia autonômica cardiovascular (grupo 2) ......

APÊNDICE F - Distribuição de diferentes medidas quantitativas de acordo com os grupos avaliados, incluindo estatísticas de comparações múltiplas entre os grupos.

APÊNDICE G - Fluxograma das porcentagens de alterações da eletrogastrografia (EGG) em relação aos grupos avaliados. 


\section{ABREVIATURAS E SIGLAS}

\begin{tabular}{|c|c|}
\hline $\mathrm{Cl}$ & coeficiente de instabilidade \\
\hline CIC-IM & célula intersticial de Cajal intramuscular \\
\hline CIC-MI & célula intersticial de Cajal mioentérica \\
\hline ClCs & células intersticiais de Cajal \\
\hline CMM & complexo motor migratório \\
\hline cpm & ciclos por minuto \\
\hline DM & diabetes mellitus \\
\hline DM1 & diabetes mellitus tipo 1 \\
\hline DM2 & diabetes mellitus tipo 2 \\
\hline DP & desvio padrão \\
\hline EGG & eletrogastrografia \\
\hline $\mathrm{FC}$ & frequência cardíaca \\
\hline FD & frequência dominante \\
\hline FFT & transformação rápida de Fourier (Fast Fourier Transform) \\
\hline GCSI & Índice de Sintomas Cardinais de Gastroparesia \\
\hline HCFMUSP & Hospital das Clínicas da Faculdade de Medicina da \\
\hline & Universidade de São Paulo \\
\hline IBGE & Instituto Brasileiro de Geografia e Estatística \\
\hline IC95\% & intervalo de confiança de $95 \%$ \\
\hline IMC & índice de massa corporal \\
\hline NA & neuropatia autonômica \\
\hline NAC & neuropatia autonômica cardiovascular \\
\hline NAD & neuropatia autonômica diabética \\
\hline P25 & percentil 25 \\
\hline P75 & percentil 75 \\
\hline
\end{tabular}


PAGI-SYM Índice de Avaliação dos Pacientes com Distúrbios do TG Superior - Índice de Gravidade dos Sintomas

PR power ratio

SNA sistema nervoso autônomo

SNP sistema nervoso parassimpático

SNS sistema nervoso simpático

TCLE Termo de Consentimento Livre e Esclarecido

TGI trato gastrointestinal

VFC variabilidade de frequência cardíaca 


\section{TABELAS}

Tabela 1 - Análise descritiva das características quantitativas estratificadas no grupo controle, incluindo média, desvio padrão, mediana, intervalo interquartl (P25-P75) e mínimo-máximo

Tabela 2 - Análise descritiva das características qualitativas estratificadas de acordo com os grupos, incluindo frequência absoluta, frequência relativa, intervalo de confiança de $95 \%$ e nível descritivo

Tabela 3 - Análise descritiva das características quantitativas estratificadas de acordo com os grupos, incluindo média, desvio padrão, mediana, intervalo interquartil (P25-P75) e nível descritivo

Tabela 4 - Análise de correlação, realizada no grupo 2, entre o total de sintomas e os parâmetros de normogastria basal, normogastria pós-prandial e PR, incluindo coeficiente de correlação, valor de $\mathrm{p}$ e número de indivíduos considerados 


\section{FIGURAS}

Figura 1 - Padrão normal de condução da onda lenta gástrica............. 12

Figura 2 - Fluxograma dos participantes incluídos no estudo ............... 26

Figura 3 - $\quad$ Aparelho de eletrogastrografia.......................................... 27

Figura 4 - Posicionamento dos eletrodos ............................................ 29

Figura 5 - Em A, análise visual de artefatos, evidenciados na linha laranja inferior, decorrentes de movimento respiratório. Em B, artefato decorrente de movimento respiratório, retirado na análise computadorizada (retângulos em vermelho)

Figura 6 - Análise do sinal da eletrogastrografia multicanal com registro contínuo. Em A, sensores bipolares; em B, sensores unipolares; em $\mathbf{C}$, movimentos respiratórios; em $\mathbf{D}$, transformação rápida de Fourier (FFT); e em E, múltiplas linhas de FFT - análise espectral contínua

Figura 7 - Boxplot e histograma da distribuição das frequências dominantes médias (cpm) basal e pós-prandial.

Figura 8 - Boxplot e histograma da distribuição da frequência dominante média $(\mathrm{cpm})$ total.

Figura 9 - Porcentagem de alterações da eletrogastrografia em relação aos grupos avaliados: a, grupo controle (voluntários saudáveis); b, grupo 1 (DM1 sem NAC); e c, grupo 2 (DM1 com NAC)

Figura 10A - Comparação do power ratio (PR) entre os grupos de indivíduos normais; de pacientes diabéticos sem NAC e de pacientes diabéticos com NAC

Figura 10B - Comparação da porcentagem de normogastria basal entre os grupos de indivíduos normais; dos pacientes diabéticos sem NAC e dos pacientes diabéticos com NAC

Figura 10C - Comparação da frequência dominante (FD) média total entre os grupos de indivíduos normais; dos pacientes diabéticos sem NAC e dos diabéticos com NAC 
Figura 10D - Comparação da porcentagem de bradigastria basal entre os grupos de indivíduos normais; de pacientes diabéticos sem NAC e de pacientes diabéticos com NAC.... 45

Figura 10E - Comparação da porcentagem de taquigastria basal entre os grupos de indivíduos normais; de pacientes diabéticos sem NAC e de pacientes diabéticos com NAC .... 46 


\section{RESUMO}

Carvalho NS. Eletrogastrografia multicanal em voluntários saudáveis e pacientes com diabetes mellitus tipo 1 [tese]. São Paulo: Faculdade de Medicina, Universidade de São Paulo; 2020.

Introdução: O diabetes mellitus (DM) é uma doença metabólica e a falta de tratamento adequado pode resultar em complicações agudas e/ou crônicas. Dentre as complicações crônicas temos a neuropatia autonômica diabética (NAD) que apresenta como manifestação mais comum a neuropatia autonômica cardiovascular (NAC) que pode ser diagnosticada por métodos não invasivos. O DM pode também ocasionar alterações das atividades motora e mioelétrica gástricas, que resultam em retardo do esvaziamento gástrico, gastroparesia diabética e surgimento de sintomas do trato digestivo superior. Estes distúrbios da atividade mioelétrica gástrica em pacientes diabéticos poderiam indicar a ocorrência de neuropatia autonômica. A eletrogastrografia (EGG) multicanal, método não invasivo que avalia a atividade mioelétrica gástrica, detecta desordens na frequência e no ritmo elétrico. No Brasil, não há estudo que tenha avaliado a atividade elétrica gástrica com EGG multicanal. Objetivo: Avaliar a EGG multicanal em voluntários saudáveis na população brasileira, em pacientes com DM tipo 1 (DM1) sem NAC e sem sintomas de gastroparesia, e em pacientes com DM1 com NAC e sintomas de gastroparesia (diagnóstico de gastroparesia confirmado pelo esvaziamento gástrico por cintilografia). Casuística e Métodos: Estudo caso-controle, incluindo 50 participantes de nossa população submetidos a EGG, sendo 20 voluntários saudáveis (grupo controle), 15 pacientes com DM1 sem NAC e sem sintomas de gastroparesia (grupo 1) e 15 pacientes com DM1 com NAC, sintomas de gastroparesia e diagnóstico de gastroparesia confirmado pelo esvaziamento gástrico por cintilografia (grupo 2). Os pacientes foram encaminhados do Ambulatório de Diabetes da Disciplina de Endocrinologia e Metabologia do Hospital da Clínicas da Faculdade de São Paulo (HCFMUSP) já com as definições previamente confirmadas de DM1 e NAC. A EGG foi realizada em dois períodos distintos, basal e pós-prandial, após ingesta de dieta de prova contendo $400 \mathrm{kcal}$. Os parâmetros avaliados foram frequência dominante (FD), porcentagem de FD e power ratio (PR) entre os períodos basal e pósprandial. Foi considerada EGG normal: normogastria (2-4 ciclos por minuto $\mathrm{cpm})>70 \%$ em ambos os períodos e PR $>1$. O esvaziamento gástrico por cintilografia foi realizado de acordo com o protocolo da Sociedade Americana de Medicina Nuclear e os sintomas foram avaliados por meio do Questionário de Índice de Sintomas Cardinais de Gastroparesia (GCSI)adaptado. Resultados: A variação da FD média total no grupo controle foi de 2,3-3,3 cpm, a porcentagem de FD em normogastria foi $>70 \%$ em ambos os períodos e o PR foi > 1 em 19 dos 20 indivíduos. Entre os pacientes do grupo $1,53,3 \%$ apresentaram EGG anormal, e entre os pacientes do grupo 
2, $87,6 \%$ apresentaram EGG anormal. A porcentagem da FD média no período basal apresentou diferença significante entre os grupos: grupo controle, 77,0-100,0\%; grupo 1, 60,0-96,3\%; e grupo 2, 57,9-85,7\% ( $p=$ $0,019)$. Em relação ao fator PR, a mediana foi de 6,0 no grupo controle, 7,0 no grupo 1 , e 0,5 no grupo $2(p<0,001)$, havendo diferença na comparação múltipla entre os indivíduos do grupo controle e os pacientes do grupo 2. Conclusões: Os pacientes com DM1 com e sem NAC podem apresentar distúrbios da atividade mioelétrica gástrica. A prevalência de disritmias gástricas é maior em pacientes com DM1 com NAC, retardo do esvaziamento gástrico e sintomas de gastroparesia, comparativamente a pacientes sem NAC e sem sintomas de gastroparesia e aos indivíduos voluntários saudáveis. A porcentagem de normogastria da FD média nos períodos basal e pós-prandial parece ser um bom parâmetro, que se associa aos sintomas de pacientes com gastroparesia diabética e NAC.

Descritores: Diabetes mellitus; Neuropatias diabéticas; Gastroparesia; Eletrodiagnóstico; Esvaziamento gástrico; Motilidade gastrointestinal. 


\section{ABSTRACT}

Carvalho NS. Multichannel electrogastrography in healthy volunteers and in patients with diabetes mellitus type 1 [thesis]. São Paulo: "Faculdade de Medicina, Universidade de São Paulo"; 2020.

Introduction: Diabetes mellitus (DM) is a metabolic disease, and a lack of appropriate treatment can result in acute and/or chronic complications. Among the chronic complications, diabetic autonomic neuropathy (DAN) commonly manifests as cardiovascular autonomic neuropathy (CAN), and can be diagnosed by noninvasive methods. DM can also cause changes in gastric motor and myoelectric activity, resulting in delayed gastric emptying, diabetic gastroparesis, and superior digestive tract symptoms. These myoelectric gastric activity disorders in diabetic patients could indicate autonomic neuropathy. Multichannel electrogastrography (EGG) is a noninvasive method to evaluate myoelectric gastric activity and detect disorders of frequency and electrical rhythm. In Brazil, no study has evaluated electric gastric activity with multichannel EGG. Objective: To evaluate multichannel EGG in healthy volunteers in the Brazilian population, in type 1 DM (DM1) patients without CAN or symptoms of gastroparesis, and in DM1 patients with CAN and symptoms of gastroparesis (diagnosis of gastroparesis confirmed by gastric emptying scintigraphy). Methods: A casecontrol study was conducted on 50 participants from the Brazilian population who underwent EGG, of which 20 were healthy volunteers (control group), 15 were CAN-free DM1 patients with no symptoms of gastroparesis (group 1), and 15 were CAN DM1 patients with symptoms of gastroparesis and a confirmed diagnosis of gastroparesis by emptying gastric scintigraphy (group 2). The patients were referred from the Diabetes Outpatient Clinic of the Department of Endocrinology and Metabolism, School of Medicine Clinical Hospital, University of São Paulo (HCFMUSP), already diagnosed with DM1 and CAN. EGG was performed at two different periods, basal and postprandial, after ingestion of a test $400 \mathrm{kcal}$ diet. The parameters evaluated were the dominant frequency (DF) and the percentage of DF and power ratio (PR) between baseline and postprandial periods. The EGG was considered normal when: normogastry (2-4 cycles per minute $(\mathrm{cpm}))>70 \%$ in both periods, and PR $>1$. Gastric emptying scintigraphy was conducted in accordance with the American Society of Nuclear Medicine protocol, and the symptoms were evaluated using the adapted Gastroparesis Cardinals Symptom Index (GCSI) questionnaire. Results: The total mean DF variation in the control group was 2.3-3.3 cpm, the percentage of DF in normogastry was $>70 \%$ in both periods, and PR was > 1 in 19 of the 20 volunteers. In Group 1,53.3\% had abnormal EGG, and in Group 2, 87.6\% had abnormal EGG. The mean DF percentage in the baseline period showed a significant difference among the groups: control group, 77.0-100.0\%; group 1, 60.0- 
96.3\%; and group 2, 57.9-85.7\% ( $p=0.019)$. As for the PR factor, the median was 6.0 in the control group, 7.0 in group 1 , and 0.5 in group 2 ( $p<$ 0.001), with a multiple comparison difference between the control group and group 2 patients. Conclusions: DM1 patients with and without CAN may present with myoelectric gastric activity disorders. The prevalence of gastric dysrhythmias is higher in patients with CAN, DM1, delayed gastric emptying and symptoms of gastroparesis, compared to patients without CAN and without symptoms of gastroparesis, and healthy volunteers. The percentage of mean DF normogastry in the basal and post-prandial periods seems to be a good parameter when associated with the symptoms of diabetic gastroparesis and CAN.

Descriptors: Diabetes mellitus; Diabetic neuropathies; Gastroparesis; Electrodiagnosis; Gastric emptying; Gastrointestinal motility. 


\section{INTRODUÇÃO}

\subsection{Neuropatia Diabética}

O diabetes mellitus (DM) é uma doença metabólica que cursa com hiperglicemia. A falta de tratamento adequado resulta em complicações agudas, como cetoacidose diabética, e crônicas, como nefropatia, retinopatia, angiopatia, neuropatia periférica e neuropatia autonômica (NA). A NA diabética (NAD) está entre as complicações menos reconhecidas, embora gere significativo impacto na sobrevida e na qualidade de vida ${ }^{1,2}$, uma vez que pode acometer todo o sistema nervoso autônomo (SNA), simpático (SNS) e parassimpático (SNP). Os órgãos, em sua maioria, são duplamente inervados, ou seja, recebem fibras simpáticas e parassimpáticas, e, por isso, a NAD manifesta-se por disfunção em diversos órgãos e sistemas, como cardiovascular, gastrointestinal, geniturinário, sudomotor e ocular 3,4 . Os efeitos da NAD são generalizados e, inicialmente, acometem os nervos mais longos, como o nervo vago, que representa cerca de $75 \%$ das atividades parassimpáticas ${ }^{5}$.

O nervo vago é uma das principais vias que levam os impulsos parassimpáticos pré-ganglionares para o trato gastrointestinal (TGI). Em geral, os neurônios motores não inervam diretamente as células musculares lisas do TGI, pois fazem conexões sinápticas com as células intersticiais de Cajal (CICs), as quais estimulam as células musculares lisas. Assim, as CICs são os transdutores pós-juncionais que recebem os impulsos dos neurônios motores entéricos, e a perda dessas células vem sendo associada a neuropatias ${ }^{6,7}$.

A neuropatia autonômica cardiovascular (NAC), manifestação mais comum e mais bem descrita da NAD e que decorre de lesão das fibras autonômicas periféricas relacionadas ao sistema cardiovascular, é definida 
como insuficiência do controle autonômico do sistema cardiovascular ${ }^{8,9}$. Atualmente, testes autonômicos não invasivos, simples, como a avaliação da variabilidade da frequência cardíaca (VFC), sensíveis tanto para o SNS como para o SNP, com boa reprodutibilidade, são utilizados no diagnóstico e acompanhamento da NAC ${ }^{10}$.

A detecção da NAC pode ser feita através da VFC por análise espectral. O resultado (amplitude do espectro) é apresentado em um diagrama de amplitude vs. frequência. Durante o exame, o traçado da frequência cardíaca (FC) é dividido em duas bandas: frequência baixa $(0,04 \mathrm{~Hz}$ a $0,15 \mathrm{~Hz})$, influenciada pelas atividades simpática e vagal; e frequência alta $(0,15 \mathrm{~Hz}$ a $0,4 \mathrm{~Hz}$ ), considerada um marcador de atividade vagal ${ }^{2,11}$.

A análise espectral permite a avaliação da VFC, em repouso e durante a realização de manobras que compõem o que se conhece por teste de Ewing, Valsalva, resposta da FC à respiração profunda e à posição ortostática, e resposta da pressão arterial à posição ortostática e ao exercício isométrico (handgrip) ${ }^{12,13}$. O uso da análise espectral tem permitido a detecção mais precoce da disfunção autonômica ${ }^{14-16}$. Um estudo demonstrou que a VFC, avaliada pela análise espectral, pode estar alterada em estados de desregulação e doença ${ }^{17}$. Esse método tem alta especificidade e alta sensibilidade ${ }^{2,11}$.

O modelo tradicional de avaliação da NAC apresenta limitações. Ao se avaliar concomitantemente dois sistemas que apresentem influência do SNA, como os sistemas digestivo e cardiovascular, procurou-se superar algumas dessas limitações ${ }^{18}$.

Desse modo, a avaliação conjunta de dados de disfunções cardiovasculares e digestivas poderia fornecer melhor compreensão das alterações do SNA nesses pacientes. O estudo do esvaziamento gástrico e da atividade mioelétrica gástrica poderia indicar possíveis diferenças e representar marcadores de disfunção autonômica em pacientes com DM tipo1 (DM1). 


\subsection{Gastroparesia Diabética}

O DM pode ocasionar alterações motoras gástricas, que resultam em alteração do esvaziamento gástrico. A gastroparesia é um distúrbio crônico, que se caracteriza pelo retardo do esvaziamento do estômago após a alimentação na ausência de obstrução mecânica, sobretudo estenose pilórica 19.

Além do DM, a gastroparesia pode ocorrer em outras situações clínicas, tais como: após intervenção medicamentosa, após cirurgia, na presença de desordens neurológicas, como Parkinson, e de doença do colágeno ou após infecção viral ou bacteriana. Ademais, em um número considerável de casos não se evidenciam condições clínicas associadas, sendo reconhecida como gastroparesia idiopática ${ }^{20}$.

Uma das causas mais comuns da gastroparesia é o DM. As ocorrências de gastroparesia diabética representam $30 \%$ do total de casos ${ }^{21}$.

Em estudo com pacientes diabéticos e indivíduos controle, dos quais 269 com DM1, 409 com DM tipo 2 (DM2) e 735 não diabéticos, as proporções cumulativas de pacientes que desenvolveram gastroparesia durante um período de 10 anos foram de 5,2\% entre os pacientes com DM1, de 1,0\% entre os pacientes com DM2, e de $0,2 \%$ entre os indivíduos controle ${ }^{22}$. A presença de gastroparesia em pacientes com DM está associada ao descontrole glicêmico entre outras complicações do diabetes, incluindo retinopatia, neuropatia periférica, disfunção vagal cardiovascular e nefropatia ${ }^{23}$.

A disfunção neuromuscular que leva ao retardo do esvaziamento gástrico decorre dos principais mecanismos envolvidos na fisiopatologia da gastroparesia, a saber: alteração do controle neural extrínseco (sobretudo da função vagal), disfunção da inervação intrínseca e de células intersticiais envolvidas no controle da função muscular gastrointestinal, e perda da função da musculatura lisa 24,25 . 
A formação de um consenso com pesquisadores de vários centros de referência em gastroparesia nos Estados Unidos da América vem contribuindo para o melhor entendimento da fisiopatologia e dos mecanismos celulares relacionados às gastroparesias diabética e idiopática ${ }^{26}$. Observou-se que a redução da densidade das CICs foi a anormalidade mais proeminente em ambas as etiologias, geralmente associada a danos nas CICs remanescentes, e também foram descritas redução da densidade de fibras nervosas, presença de infiltrado inflamatório e fibrose do estroma ${ }^{27}$. A redução das $\mathrm{CICs}$ pode ser de particular importância funcional para o desenvolvimento da gastroparesia, considerando seu papel central na geração e propagação de ondas lentas. Essas anormalidades fornecem uma base patológica racional para a gênese das arritmias na gastroparesia ${ }^{28}$.

Estudos prévios evidenciaram desmielinização segmentar e degeneração axonal em fibras nervosas vagais, nos plexos tanto mientéricos como submucosos do TGI de pessoas com DM e alterações estruturais nos axônios das fibras vagais em modelos experimentais de ratos diabéticos. Em ambos, pacientes e modelos animais de diabetes, o número de células nos gânglios vagais motores e nos gânglios simpáticos estava reduzido ${ }^{29,} 30$.

Sintomas gastrointestinais, tais como plenitude pós-prandial, náusea, vômitos, eructação, inchaço, dor abdominal, diarreia e constipação, são comumente descritos, sendo relatados em $5 \%$ a $12 \%$ dos portadores de DM, assim como distúrbios da motilidade gástrica e aceleração ou retardo do esvaziamento gástrico ${ }^{31}$.

Os principais sintomas em pacientes diabéticos com gastroparesia incluem: dor abdominal, saciedade precoce, plenitude pós-prandial, náusea, vômitos, eructação e inchaço. Alguns desses sintomas sobrepõem-se aos da dispepsia funcional, fazendo com que a descrição da epidemiologia seja desafiadora ${ }^{19}$.

Em relação ao DM1, a prevalência de sintomas sugestivos de gastroparesia está em torno de $25 \%$, os sintomas cardinais (náusea, vômitos, plenitude gástrica, perda de apetite, inchaço e distensão abdominal) ocorrem 
em $10 \%$, e o diagnóstico clínico de gastroparesia é realizado em cerca de $5 \%$ dos pacientes ${ }^{23}$.

Alguns estudos evidenciam baixa qualidade de vida em pacientes com gastroparesia, sendo mais pronunciada em pacientes diabéticos, comparativamente aos não diabéticos, que destacam maior prevalência de insônia e depressão ${ }^{32,33}$.

Os sintomas clínicos de gastroparesia incluem náusea, vômitos, saciedade precoce, plenitude pós-prandial, bloating, eructação e desconforto em andar superior do abdome. A análise da gravidade dos sintomas e os resultados de qualidade de vida são importantes para avaliar a eficácia de tratamentos para distúrbios gastrointestinais ${ }^{34}$. No decorrer dos anos, houve a necessidade de desenvolver medidas psicométricas sólidas dos sintomas, classificadas pelos pacientes para avaliar a eficácia das terapias e monitorar os resultados clínicos em pacientes com gastroparesia ${ }^{35,36}$.

Diversas escalas de sintomas foram desenvolvidas para avaliar pacientes com gastroparesia, mas, em sua maioria, são limitadas em relação à qualidade de vida e dependem de avalições clínicas dos sintomas desencadeados, feitas pelo paciente, além de não serem avaliadas quanto a confiabilidade e validade ${ }^{37-39}$.

Dessa maneira, um estudo com maior confiabilidade e validade foi desenvolvido para avaliar as características de uma escala de gravidade de sintomas, o Índice de Sintomas Cardinais da Gastroparesia (GCSI), para uso em estudos clínicos de gastroparesia. O GCSI foi desenvolvido como parte de um projeto maior, o desenvolvimento do Índice de Avaliação dos Pacientes com Distúrbios do TGI Superior - Índice de Gravidade dos Sintomas (PAGISYM) $40,41$.

O GCSI consiste de três subescalas do PAGI-SYM, selecionadas para medir sintomas importantes relatados na gastroparesia: náusea/vômitos (composto por três itens: vontade de vomitar, vontade de vomitar mas não consegue, e vômitos), plenitude/saciedade precoce (composto por quatro itens: plenitude, não é capaz de terminar uma refeição, sente-se muito cheio 
após uma refeição, e perda de apetite), e bloating (composto por dois itens: distensão e estômago visivelmente maior), adaptados para a língua portuguesa.

O método padrão de referência para o diagnóstico de gastroparesia é o esvaziamento gástrico por cintilografia. Estudos demonstram que os sintomas de gastroparesia estão fracamente correlacionados com o retardo do esvaziamento gástrico. Essa fraca associação pode sugerir que diferentes mecanismos estejam envolvidos nesse processo ${ }^{42}$.

O esvaziamento gástrico reflete a coordenação da função de fundo, corpo, antro, piloro e duodeno. Os principais eventos para o esvaziamento gástrico são: relaxamento e acomodação do fundo, contração antral, abertura do piloro e coordenação antropilórica-duodenal. Nesse contexto, o sistema nervoso, que controla o músculo liso gástrico, tem papel fundamental no esvaziamento gástrico. O sistema nervoso entérico está conectado ao sistema nervoso central por meio de neurônios sensoriais, os quais enviam fibras aferentes, que transportam sensações viscerais, tais como dor, plenitude e náusea, e vias eferentes simpáticas e parassimpáticas, que modulam motilidade, secreção e circulação ${ }^{43}$.

Outros métodos não cintilográficos podem avaliar o esvaziamento gástrico, tais como: estudo ultrassonográfico ${ }^{44}$, teste respiratório ${ }^{45}$, ressonância nuclear magnética ${ }^{46} \mathrm{e}$, mais recentemente, uso de cápsula com sinais de pressão e de $\mathrm{pH}$ enviados por telemetria ${ }^{47}$. Outro teste, a eletrogastrografia (EGG), descrita com mais detalhes posteriormente neste trabalho, é complementar e pode inferir desordens na motilidade gástrica pela análise da atividade mioelétrica gástrica ${ }^{48}$.

Apesar dos avanços na compreensão dos mecanismos e da fisiopatologia da gastroparesia, ainda existe um incompleto entendimento em relação a mecanismos celulares, inconsistências entre estudos e possíveis diferenças entre grupos etiológicos. A individualização de cada caso é o melhor caminho, por meio da identificação do comprometimento funcional e do reconhecimento de alterações da atividade elétrica gástrica e da redução 
concomitante da acomodação gástrica entre pacientes que apresentam sintomas sugestivos de gastroparesia ${ }^{24}$.

\subsection{Atividade Mioelétrica Gástrica}

O TGI pode ser considerado um sistema eletricamente ativo, com diversos tipos celulares responsáveis pela coordenação e propagação da atividade elétrica ${ }^{49}$. A atividade elétrica gástrica consiste de atividade rítmica espontânea, que determina tempo e frequência contrátil do estômago, e de potenciais de ação da musculatura gástrica ${ }^{50}$.

A musculatura gástrica apresenta uma variação contínua do potencial elétrico, caracterizada por um ciclo de despolarização e repolarização, que se inicia na grande curvatura, na porção proximal do corpo, e migra circunferencial e longitudinalmente no sentido do piloro. Essa atividade elétrica é conhecida como atividade elétrica de controle, ritmo elétrico gástrico ou onda lenta (slow wave), em razão de sua baixa frequência ${ }^{51}$.

Toda a musculatura gástrica, a partir do corpo, é capaz de gerar potenciais semelhantes. As frequências dos potenciais gerados em outras regiões são menores que as do corpo proximal e, por isso, a atividade elétrica na região da grande curvatura do corpo assume, normalmente, o papel de "marca-passo" dominante.

As ondas lentas propagam-se, longitudinalmente, no sentido corpoantro, em direção ao piloro, e no sentido transversal, da grande para a pequena curvatura, em intervalos de cerca de 20 segundos, portanto com frequência de 3 ciclos por minuto ( $\mathrm{cpm}$ ), no homem, e velocidade constante de, aproximadamente, $3 \mathrm{~mm} / \mathrm{s}$, de modo que sucessivas ondas frontais se espaçam uniformemente em intervalos de cerca de $6 \mathrm{~cm}$. No entanto, no antro há aceleração da velocidade e a distância entre as ondas torna-se maior. Usualmente, as ondas lentas não excitam o fundo gástrico ${ }^{52}$. 
O ritmo elétrico gástrico controla o momento, a frequência máxima de ocorrência e o sentido de propagação das contrações da musculatura gástrica, desempenhando papel importante na função motora do estômago e ocorrendo continuamente e de modo independente da presença de contração 53.

O potencial de ação inicia-se quando o potencial de onda lenta aumenta acima do limiar (-35 mV, aproximadamente), ocorrendo a contração da musculatura gástrica. A atividade elétrica associada a contrações caracteriza-se por potenciais de oscilação rápida (spikes), sendo também conhecida por potenciais de ação ou, ainda, atividade elétrica de resposta ${ }^{54,55}$.

As variações do ritmo elétrico gástrico são referidas como disritmias gástricas ${ }^{56}$. Embora ainda se discuta qual a frequência de ondas lentas considerada normal em seres humanos, a faixa de referência comumente citada é entre 2,5 cpm e 3,6 cpm, de tal forma que bradigastria e taquigastria são definidas como padrões fora desse intervalo ${ }^{52}$.

Os primeiros registros de potenciais transmembrana da musculatura gástrica, observados com microeletrodos, confirmaram a atividade mioelétrica gástrica in vivo e demonstraram as variações que caracterizam a oscilação cíclica da musculatura gástrica: uma rápida despolarização, seguida de repolarização parcial, com subsequente manutenção de despolarização prolongada (fase de platô) e, finalmente, de repolarização ${ }^{57}$.

O evento inicial - despolarização ascendente - raramente excede 50 $\mathrm{mV}$ acima do potencial de repouso inicial, aproximando-se, em geral, a -20 $\mathrm{mV}$ antes que a fase de repolarização parcial se inicie. A fase de platô é um período de despolarização sustentada, que pode ter duração variável, entre 3 segundos e 20 segundos. As características e a duração da fase de platô dependem de vários fatores, tais como: local de origem, frequência de despolarização (pacing), parâmetros físicos do meio, como pH, temperatura e composição iônica, e agonistas, como acetilcolina ${ }^{58}$. 
A contração da célula muscular lisa ocorre quando o nível de despolarização ou fase de platô alcança determinado limiar. Para que possa haver contração durante a passagem da onda lenta, é necessário que a despolarização atinja limiar de, pelo menos, $40 \mathrm{mV}$. A partir desse potencial, verifica-se aumento abrupto da geração de força contrátil com pequena variação do potencial. A amplitude e a duração do potencial em platô determinam a magnitude de influxo de cálcio, com aumento da concentração intracelular de cálcio que ativa a cadeia leve de miosina, levando à formação de pontes e causando a contração ${ }^{59}$.

O sentido de propagação e a frequência máxima com que podem ocorrer as contrações da musculatura lisa dependem de a onda lenta e de a estimulação neuro-hormonal sobre a célula muscular lisa em cada ciclo determinarem a presença e a força de contração ${ }^{53}$. O estímulo neurohormonal é mediado pelo sistema nervoso entérico e modulado pelo SNS e pelo SNP. Essa inervação tanto simpática como parassimpática do sistema nervoso entérico pode alterar a secreção e a motilidade do estômago.

As ondas lentas rítmicas (espontâneas), que dão início às contrações gástricas, são originadas nas CICs, que estão distribuídas por todo o TGI, regulam a excitabilidade do músculo liso e contribuem para a organização da motilidade. As CICs têm duas localizações preferenciais: mioentérica e inrtramuscular. Na localização mioentérica (CIC-MI), as CICs estão próximas ao plexo mioentérico, entre as camadas musculares circular e longitudinal, e geram as ondas lentas. Na localização intramuscular (CIC-IM), as CICs estão distribuídas entre os feixes de músculo liso no estômago e no intestino delgado e localizam-se no plexo muscular profundo, intimamente ligadas aos terminais nervosos entéricos, formando contatos semelhantes às sinapses e intermediando a neurotransmissão motora entérica (entre neurônios e músculo liso) ${ }^{50}$.

Dessa forma, as ClCs unem-se em redes abundantes em torno do plexo mioentérico gástrico ${ }^{60}$, e a propagação elétrica dentro dessas camadas é facilitada por uma subclasse adicional de CICs septais, que encerram e 
ligam os feixes musculares. Em indivíduos saudáveis, as ondas lentas gástricas surgem em região definida como marca-passo, localizada no corpo médio-superior da grande curvatura (Figura 1) ${ }^{61}$. A partir desse local, a propagação anterógrada é facilitada por gradiente de frequência subjacente das CICs. Essa região é considerada marca-passo dominante, pois as $\mathrm{CICs}$ situadas nessa parte têm frequência intrínseca alta, com velocidade e amplitude também altas, levando ao surgimento das ondas lentas, com velocidade lenta e de baixa amplitude. Além disso, as CICs ligam-se ao sincício da musculatura lisa por meio de gap junction. A interpretação de estudos morfológicos, funcionais e de alterações genéticas demonstrou relação das células mesenquimais de Cajal com o ritmo elétrico básico em todo o trato digestivo ${ }^{62}$. Acredita-se que, nas $\mathrm{CICs}$, o cálcio ative os canais de cloreto, produzindo potencial de marca-passo, como no coração, e o comprometimento dessa atividade por interrupções na rede de $\mathrm{CICs}$ ou desagregação no gradiente de frequência pode induzir desacoplamento físico ou funcional dessa atividade do marca-passo, afetando a eficiência da motilidade gástrica e, assim, provocando alterações na taxa rítmica da atividade elétrica gástrica ${ }^{63,64}$.

A atividade motora gástrica pode ser detectada nos estados de jejum e pós-prandial. Durante a fase de jejum, o padrão da atividade motora é cíclico, conhecido como complexo motor migratório (CMM). Na fase pós-prandial, o CMM é substituído pela atividade motora tônica. A presença do bolo alimentar no estômago propicia aumento da pressão intragástrica, estimulando sensores de tensão que levam ao relaxamento da musculatura lisa do estômago proximal, por via vagovagal reflexa ${ }^{65}$. Os movimentos peristálticos gástricos produzidos pela excitação de receptores de tensão e pelo reflexo vagovagal seguem do corpo em direção ao antro, mantendo ritmo de 3 com 66,67 .

A EGG é o método utilizado para registrar a atividade elétrica gástrica, cuja curva fisiológica consiste em ondas regulares com frequência de, aproximadamente, $3 \mathrm{cpm}$. 

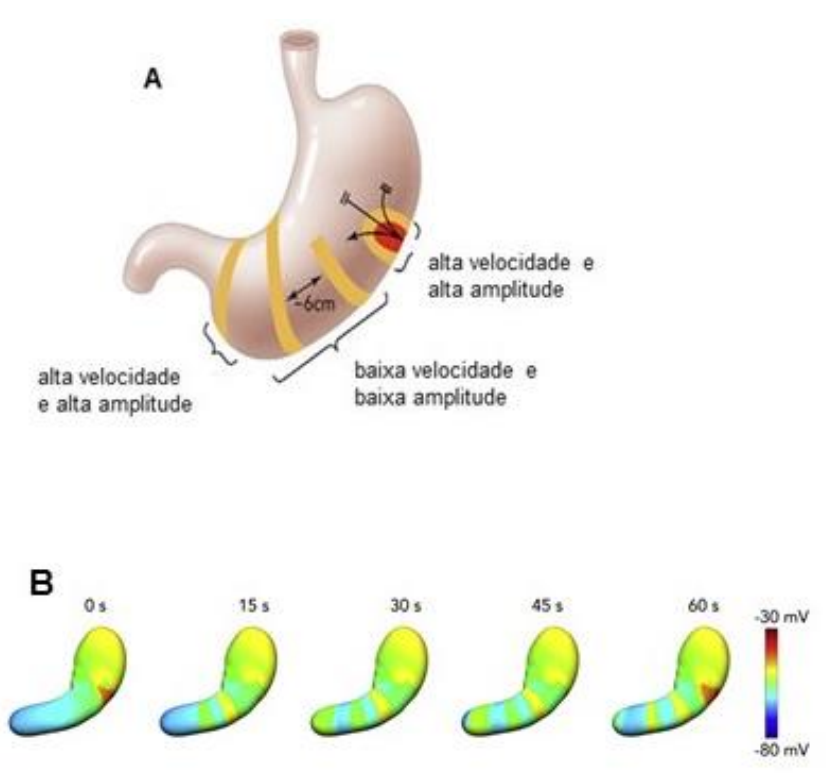

Fonte: Adaptado de O'Grady et al., $2015^{68}$.

Figura 1 - Padrão normal de condução da onda lenta gástrica ${ }^{52,61}$. Em A, as ondas lentas surgem em uma região de marca-passo na grande curvatura do corpo. As ondas lentas propagam-se, inicialmente, em todas as direções e, rapidamente, no eixo circunferencial, formando completas ondas em anéis no corpo médio. As múltiplas ondas acumulam-se, espaçadas aproximadamente $6 \mathrm{~cm}$ entre si, antes da transição para ativação rápida no antro. Em $\mathbf{B}$, simulação de ondas lentas em um modelo de estômago virtual, com base em tempos genéricos de ativação de ondas lentas a partir de experimentos humanos ${ }^{69}$. A cor vermelha representa a atividade despolarizada e a cor azul representa os potenciais de membrana em repouso

\subsection{Eletrogastrografia}

A EGG é técnica não invasiva, que avalia a atividade mioelétrica do estômago por meio de eletrodos colocados na superfície abdominal ${ }^{70}$.

Em 1922, Alvarez e Mahoney ${ }^{71}$ descreveram os primeiros registros da EGG, mas foi somente na década de 1950 que Davis et al. 72 iniciaram os primeiros estudos para sistematizar a técnica, que, a partir de 1990, com a 
introdução da análise computadorizada do sinal, tornou-se mais popularizada 73.

Um estudo revisou numerosos achados publicados na literatura sobre a validade da $E G G$, incluindo a relação entre a $E G G$ e o registro na serosa interna das ondas lentas do estômago, e a relação com suas contrações ${ }^{74}$. Em 2000, Lin e Chen ${ }^{75}$ correlacionaram o registro na serosa com a EGG, avaliando a resposta pós-prandial da atividade mioelétrica gástrica. Dessa maneira, o conceito inicial de que as variações de potencial registradas estavam sempre associadas à presença de contrações gástricas foi alterado. A partir do registro simultâneo da EGG, da atividade elétrica com eletrodos implantados cirurgicamente e da atividade contrátil antral em pacientes submetidos a laparotomia demonstrou-se que a frequência do sinal da EGG era semelhante àquela obtida por meio dos eletrodos implantados na serosa, mas não se alterava na presença ou na ausência de contrações ${ }^{76,77}$. Outro estudo simultâneo da atividade contrátil e da EGG cutânea evidencia que a amplitude do sinal da EGG aumenta quando ocorrem contrações gástricas, demonstrando que a atividade elétrica de resposta (potenciais de ação) também se reflete na EGG por aumento na amplitude da onda sinusal. O sinal da EGG pode, assim, ser considerado um somatório de ondas elétricas que migram ao longo do estômago, gerado pela atividade elétrica de controle (onda lenta) e pela atividade elétrica associada a contrações ${ }^{78-80}$.

O registro da atividade mioelétrica gástrica com eletrodos cutâneos está sujeito a inúmeros artefatos de movimento e interferências elétricas de outros órgãos, além de a interpretação do sinal ser difícil, tendo em vista sua pequena amplitude. Tais limitações na análise do sinal da EGG levaram à aplicação de modelos matemáticos de análise do sinal elétrico, que facilitaram a interpretação da EGG. Dentre esses modelos, o mais empregado e difundido foi a aplicação da análise espectral de frequência, utilizando a transformação rápida de Fourier (FFT, do inglês Fast Fourier Transform), que analisa a potência de cada frequência que compõe o sinal ${ }^{81}$. A aplicação da análise espectral contínua na interpretação da EGG passou a ser o modo mais difundido, porque permite o registro gráfico ao longo do tempo das variações 
da frequência da atividade mioelétrica gástrica ${ }^{82,83}$. A aplicabilidade e a reprodutividade do método dependeram do desenvolvimento tecnológico ao longo desses anos, da maneira como o exame passou a ser registrado, com configurações apropriadas do equipamento, novos amplificadores e filtros, e da utilização de equipamentos multicanais com eletrodos de caráter bipolar, que oferecem melhor qualidade de sinal ${ }^{48,75,84-86 .}$

\subsection{Distúrbio da Atividade Mioelétrica Gástrica}

Distúrbios da motilidade gastrointestinal, doenças funcionais do TGI ou estímulos indutores podem alterar a atividade mioelétrica do estômago, levando a anormalidades na EGG ${ }^{87,88}$. A frequência normal das ondas lentas em humanos é de $3 \mathrm{cpm}$. Anormalidades na atividade mioelétrica gástrica incluem disritmias, que podem ser classificadas em bradigastria, taquigastria e arritmia $73,89,90$.

Estudos que avaliaram o registro da atividade mioelétrica gástrica com eletrodos na serosa definiram como normogastria as frequências entre $2 \mathrm{cpm}$ e $4 \mathrm{cpm}$, como bradigastria as frequências entre $1 \mathrm{cpm}$ e $2 \mathrm{cpm}$, como taquigastria as frequências entre $4 \mathrm{cpm}$ e $9 \mathrm{cpm}$, e como arritmia as ondas planas e irregulares ${ }^{73,91,92}$. No entanto, a variação de frequência da atividade mioelétrica gástrica considerada normal vem sendo amplamente relatada

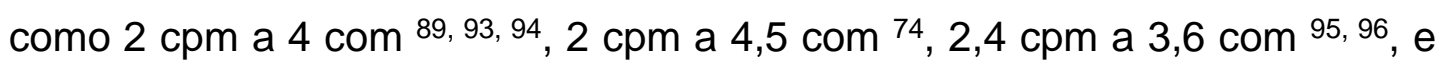
$2,4 \mathrm{cpm}$ a 3,7 $\mathrm{com}^{97}$. Essa variação de frequência pode alterar os valores da porcentagem de normogastria, bradigastria e taquigastria na análise da EGG. Assim sendo, torna-se de extrema importância a definição da faixa de normogastria, pois a partir desses valores os parâmetros finais da EGG serão calculados.

Nas últimas décadas, os conhecimentos adquiridos sobre eletrofisiologia gástrica humana contribuíram para a formação de critérios para realização e interpretação dos testes de avaliação da função elétrica gástrica ${ }^{78}$. Com isso, a $E G G$ vem se mostrando útil na triagem e no 
diagnóstico de transtornos de motilidade, e, apesar de algumas limitações, reflete de forma confiável a frequência relacionada à onda lenta propagada no estômago. Por essa razão, o foco primário da EGG vem sendo a análise da frequência dominante (FD) da onda lenta e sua estabilidade ${ }^{98}$.

Em voluntários normais, estudos da EGG permitiram estabelecer 0 padrão de normalidade e contribuíram para o desenvolvimento de estudos experimentais, visando ao esclarecimento dos mecanismos de produção das disritmias gástricas.

Distúrbios do ritmo das ondas lentas gástricas associados à deficiência da contração antral são demonstrados em pacientes com DM. A melhora dos sintomas com terapia medicamentosa correlacionada com a normalização do ritmo das ondas lentas, mas nem sempre com a normalização do esvaziamento gástrico, sugere a importância das disritmias gástricas na gênese da gastroparesia diabética ${ }^{99}$.

A maior frequência de disritmias gástricas em pacientes com gastroparesia diabética, com lesões dos plexos mioentéricos comprovados em estudo histopatológico, sugere que alterações da inervação gástrica estejam associadas a distúrbios do ritmo elétrico gástrico ${ }^{100,101 .}$

Estudos eletrofisiológicos atuais com a EGG identificaram arritmias, contrações pilóricas prolongadas e coordenação prejudicada entre antro e duodeno, demonstrando clara associação entre parâmetros arrítmicos da EGG e gastroparesia ${ }^{102}$. Além disso, a gravidade de perda das CICs relacionou-se com a presença de arritmias avaliada pela EGG ${ }^{103}$.

O acometimento do nervo vago, eventualmente encontrado em pacientes diabéticos, pode fazer com que ele passe a enviar sinais incoordenados, levando a redução das contrações antrais, tônus gástrico diminuído, descoordenação antroduodenal, hipomotilidade antral e espasmo do piloro, e desbalanço na liberação de hormônio pós-prandial, o que pode levar a retardo do esvaziamento gástrico. Todas essas alterações podem modificar a função do marca-passo gástrico, causando disritmias elétricas, 
perda do acoplamento eletromecânico e comprometimento das contrações gástricas ${ }^{104}$.

Em pacientes vagotomizados, a morfologia do sinal é diferente e ocorrem irregularidades no ritmo elétrico. Tais alterações persistem por dois anos após a vagotomia e incluem a ocorrência de frequência persistentemente elevada do potencial elétrico ${ }^{105}$.

O primeiro estudo clínico em larga escala com emprego de análise espectral contínua da EGG avaliou pacientes com sintomas dispépticos crônicos, com predomínio de náusea e vômitos recorrentes de etiologia indeterminada. Alterações da atividade mioelétrica gástrica foram detectadas em $48 \%$ dos pacientes avaliados, incluindo episódios de taquigastria, instabilidade da frequência de onda lenta e ausência do aumento da intensidade do sinal após refeição de prova. Essa última anormalidade correlacionou-se com o retardo do esvaziamento gástrico ${ }^{87}$.

A EGG não permite o diagnóstico de uma doença específica, mas foi descrita a ocorrência de distúrbios na frequência e no ritmo elétrico gástrico em outras condições clínicas, com alterações da função motora gástrica, tais como anorexia nervosa, dispepsia funcional, gastroparesia de etiologias diversas (diabética, idiopática, isquêmica), e pseudo-obstrução intestinal crônica ${ }^{106-108 .}$

Muito do que se sabe sobre arritmia gástrica, particularmente em doenças humanas, continua a ser derivado da EGG até os dias atuais. Lesões de elementos do sistema nervoso entérico, tais como as verificadas na neuropatia diabética, podem também estar associadas a anormalidades da atividade mioelétrica gástrica, mas, até o momento, nenhum estudo avaliou a atividade mioelétrica gástrica com EGG multicanal em pacientes com DM1 e NAC. 


\subsection{Relevância do Estudo}

Os estudos citados anteriormente são, em sua maioria, americanos ou europeus. Em revisão dos dados demográficos do Brasil, publicados pelo Instituto Brasileiro de Geografia e Estatística (IBGE) em 2010, observou-se que a composição étnica e racial da sociedade brasileira é resultado de uma confluência de pessoas de origens étnicas diferentes, como povos indígenas, portugueses europeus, árabes e japoneses, sendo 33\% de origem ameríndia, $28 \%$ de origem africana e $39 \%$, europeia ${ }^{109}$. Esse achado colocou em dúvida se os parâmetros de normalidade da EGG encontrados na literatura deveriam ser utilizados no Brasil. Os estudos já realizados no País 49, 107, 110 utilizaram equipamentos de EGG com apenas um canal. Não há estudos com EGG multicanal na população brasileira, portanto este estudo tem como um dos objetivos avaliar a atividade mioelétrica gástrica de voluntários saudáveis e definir parâmetros de normalidade com EGG multicanal em uma população brasileira.

A gastroparesia diabética é pouco reconhecida e em geral é investigada a partir de queixas dos pacientes, quando os sintomas são limitantes e comprometem a qualidade de vida. Nesse estágio, a maioria dos pacientes já apresenta NAC instalada, diagnosticável pela análise espectral. A EGG, por ser exame não invasivo, é um método potencialmente capaz de identificar alterações gástricas causadas pelo DM, pois analisa as vias acometidas pela NAD. Não obstante, a análise comparativa das alterações na EGG em pacientes com DM1, com sintomas de gastroparesia (gastroparesia diabética confirmada por meio de cintilografia) e NAC e em pacientes com DM1 sem sintomas de gastroparesia e sem NAC ainda não foi estudada. Recentemente, a EGG e os testes de função autonômica vêm sendo propostos como medidas não invasivas para avaliação de gastropatias no DM. Sob essa perspectiva, este estudo tem também como objetivo identificar modificações precoces na EGG e potenciais implicações clínicas que possam contribuir para o reconhecimento precoce da neuropatia diabética gástrica. 
Assim, o presente estudo avaliará voluntários saudáveis comparativamente a um grupo de pacientes com DM1 com NAC e gastroparesia diagnosticada por meio de cintilografia gástrica, bem como a outro grupo de pacientes com DM1 sem NAC e sem sintomas sugestivos de gastroparesia, ou seja, um grupo intermediário entre os voluntários saudáveis e os pacientes comprovadamente com gastroparesia. 
2 OBJETIVOS 


\section{OBJETIVOS}

O objetivo geral deste estudo é:

- Avaliar a EGG multicanal em voluntários saudáveis na população brasileira, em pacientes com DM1, sem NAC e sem sintomas de gastroparesia, e em pacientes com DM1, NAC, sintomas de gastroparesia e confirmação do diagnóstico de gastroparesia pelo esvaziamento gástrico por cintilografia.

Os objetivos específicos são:

- Comparar os resultados da EGG entre os dois grupos de pacientes e o grupo de voluntários saudáveis, e

- Avaliar a correlação entre os sintomas e os resultados da EGG no grupo com DM1, NAC, sintomas de gastroparesia e confirmação do diagnóstico de gastroparesia pelo esvaziamento gástrico por cintilografia. 


\section{CASUÍSTICA E MÉTODOS}




\section{CASUÍSTICA E MÉTODOS}

\subsection{Sujeitos do Estudo}

\subsubsection{Pacientes}

A captação dos pacientes foi realizada inicialmente por meio do Banco de Dados do Ambulatório de Diabetes da Disciplina de Endocrinologia e Metabologia do Hospital das Clínicas da Faculdade de Medicina da Universidade de São Paulo (HCFMUSP), onde os pacientes são convidados aleatoriamente a participar de análise espectral para avaliação de NAC.

No momento da pesquisa, 96 pacientes com DM1 faziam parte desse Banco de Dados e foram selecionados a partir de critérios de NAC, esvaziamento gástrico por cintilografia e dados do questionário de GCSIadaptado (Figura 2; ANEXO A). Responderam ao GCSI-adaptado os pacientes que não tinham outro critério de exclusão. Ao final foram incluídos 30 pacientes com DM1.

\subsubsection{Diagnóstico de NAC}

O diagnóstico foi feito por meio de: análise espectral, descrita anteriormente, que avalia a VFC em repouso; teste de Valsalva; resposta da FC à respiração profunda e à posição ortostática; e resposta da pressão arterial à posição ortostática. O diagnóstico de NAC é realizado quando pelo menos três dos testes estão alterados ${ }^{8,11,12}$. 


\subsubsection{Esvaziamento gástrico por cintilografia}

O esvaziamento gástrico por cintilografia foi realizado no Departamento de Medicina Nuclear do HCFMUSP, de acordo com o protocolo do serviço, que cumpre os padrões descritos a seguir.

O exame foi realizado com a ingestão de refeição padronizada contendo o radioisótopo tecnécio-99 após jejum. A Sociedade de Neurogastroenterologia e Motilidade e a Sociedade de Medicina Nuclear recomendam como refeição padrão $255 \mathrm{kcal}$, com baixo teor de lipídeo: ovos mexidos (2 unidades $=120 \mathrm{~g}$ ) marcados com $0,5 \mathrm{mCi}$ de tecnécio-99-S de coloide de radioisótopo, duas fatias de pão branco, $30 \mathrm{~g}$ de geleia de morango, e $120 \mathrm{ml}$ de água. A quantidade de radioisótopo que permanece no estômago foi mensurada em 0 minuto, 30 minutos, 60 minutos, 120 minutos, 180 minutos e 240 minutos, e o diagnóstico de gastroparesia foi considerado nos tempos de 60 minutos, 120 minutos, 180 minutos e 240 minutos se houvesse, respectivamente, $90 \%, 60 \%, 30 \%$ e $10 \%$ ou mais de resíduos da refeição 20 , 111.

\subsubsection{Questionário de Índice de Sintomas Cardinais de Gastroparesia}

Os pacientes foram interrogados de acordo com o questionário GCSIadaptado (ANEXO A), em que uma escala de sintomas variando de 0 ponto (nenhum) a 5 pontos (muito grave) foi usada para classificar a gravidade de cada item. Foram questionados os sintomas referidos no período das duas últimas semanas. As pontuações foram calculadas pelo total dos itens em cada escala. $O$ intervalo de pontuações foi entre 0 e 5 , em que as pontuações mais altas refletem a percepção de pior gravidade de sintomas. 


\subsubsection{Separação dos pacientes em grupos}

Os pacientes foram divididos em dois grupos:

- Grupo 1, composto por 15 pacientes com DM1, análise espectral sem NAC e sem sintoma de gastroparesia pelo GCSI-adaptado; e

- Grupo 2, composto por 15 pacientes com DM1, análise espectral com NAC, com sintoma de gastroparesia pelo GCSI-adaptado e diagnóstico de gastroparesia confirmado pelo esvaziamento gástrico por meio de cintilografia.

\subsubsection{Critérios de inclusão dos pacientes}

1. Idade $>18$ anos $e<60$ anos.

2. Pacientes com DM1 e análise espectral realizada previamente.

3. Paciente com NAC instalada, sintoma de gastroparesia pelo GCSIadaptado e retardo do esvaziamento gástrico comprovado por cintilografia.

4. Paciente sem NAC e sem sintoma de gastroparesia pelo GCSI-adaptado.

5. Pacientes com índice de massa corporal (IMC) $<30,0 \mathrm{~kg} / \mathrm{m}^{2}$.

\subsubsection{Critérios de exclusão dos pacientes}

1. Pacientes com NAC, sem sintoma de gastroparesia pelo GCSI-adaptado esvaziamento gástrico por cintilografia normal.

2. Pacientes sem NAC e com sintoma de gastroparesia pelo GCSI-adaptado.

3. Cirurgia gástrica prévia.

4. Pacientes com sintomas de gastroparesia por causas obstrutivas.

5. Evidência clínica de outras afecções associadas que comprometam a função motora gástrica, como: hipertensão portal, esclerose sistêmica progressiva, insuficiência renal crônica, insuficiência cardíaca congestiva, doença pulmonar obstrutiva crônica e distúrbios da tireoide.

6. Gravidez e lactação.

7. Etilismo ( $30 \mathrm{~g} / \mathrm{dia}$ para homens e $15 \mathrm{~g} /$ dia para mulheres). 
8. Doença psiquiátrica grave.

9. Sequelas de acidente vascular cerebral.

10. Medicamentos que possam interferir na função motora gástrica, como: procinéticos, inibidores de bomba de prótons e analgésicos narcóticos (suspensos por 3 dias, 7 dias e 3 dias, respectivamente, antes do estudo).

Este projeto foi submetido a análise pela Comissão de Ética do HCFMUSP e todos os pacientes que aceitaram participar assinaram o Termo de Consentimento Livre e Esclarecido (TCLE).

\subsubsection{Voluntários saudáveis}

No total, foram avaliados 20 voluntários saudáveis (grupo controle), incluindo alunos, familiares de pacientes e funcionários do Centro de Diagnóstico de Gastroenterologia da Divisão de Gastroenterologia e Hepatologia do HCFMUSP, estratificados por idade e sexo. Nenhum dos indivíduos apresentava sintomas de gastroparesia ou evidência clínica de doença do aparelho digestivo ou de outra afecção capaz de afetar a função gastrointestinal.

Todos os sujeitos participantes do estudo assinaram o TCLE antes da realização de qualquer procedimento relacionado ao estudo (número da aprovação: 2.133.229).

A distribuição dos indivíduos incluídos no estudo está ilustrada na Figura 2. 


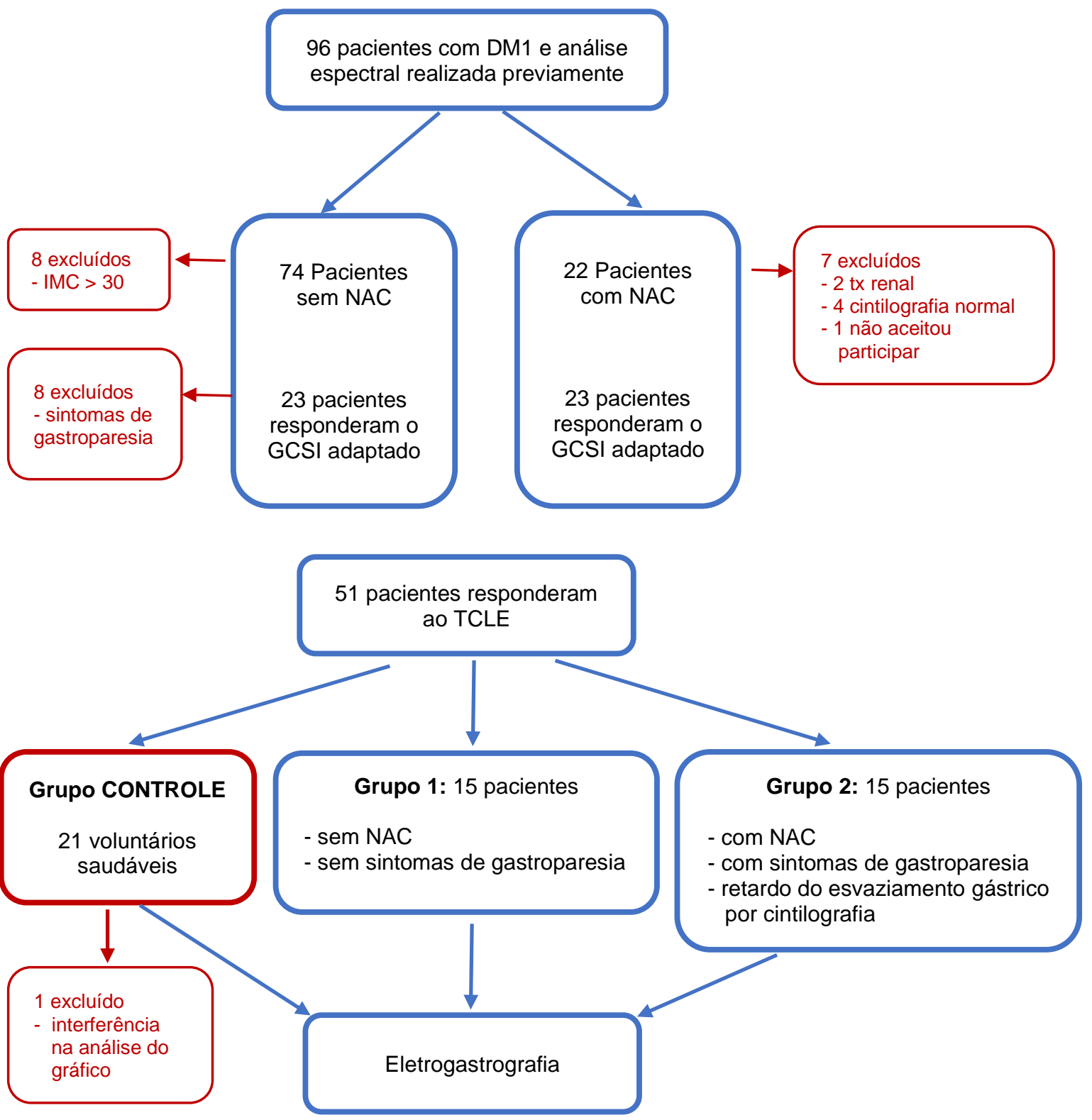

DM1 - diabetes mellitus tipo 1; GCSI adaptado - índice de sintomas cardinais da gastroparesia; NAC neuropatia autonômica cardiovascular; tx - transplante.

Figura 2 - Fluxograma dos participantes incluídos no estudo 


\subsection{Métodos}

\subsubsection{Desenho do estudo}

Trata-se de um estudo caso-controle. Os voluntários saudáveis (grupo controle) e os diabéticos sem NAC (grupo 1) foram submetidos a EGG multicanal para estudo da atividade mioelétrica gástrica. Os indivíduos com NAC (grupo 2) foram submetidos a EGG multicanal e a estudo do esvaziamento gástrico por cintilografia.

\subsubsection{Realização da eletrogastrografia}

O exame de EGG foi realizado no Centro de Diagnóstico de Gastroenterologia da Divisão de Gastroenterologia e Hepatologia do HCFMUSP. A EGG multicanal foi realizada por meio do sistema de EGG Polygraf Solar EGG module (Laborie/Medical Measurement Systems BV, Enschede, Holanda), que compreende seis eletrodos bipolares, sendo um referência, um eletrodo ground, e uma cinta para registro do movimento respiratório (Figura 3).

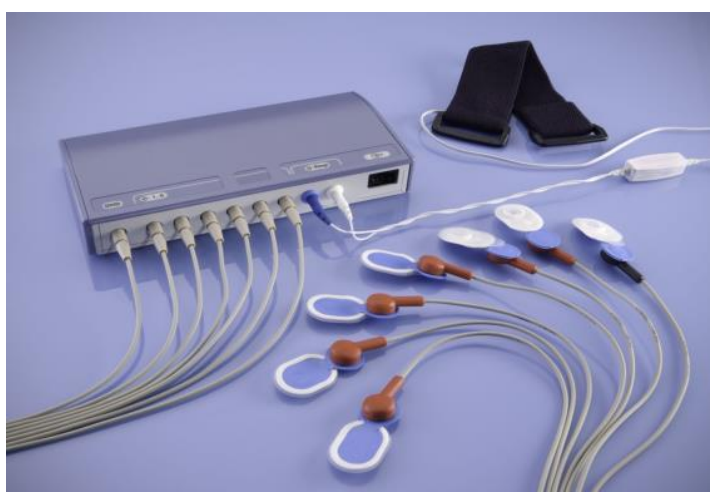

Figura 3 - Aparelho de eletrogastrografia 


\subsubsection{Preparo}

Os procedimentos foram realizados com jejum de, pelo menos, oito horas.

Os pacientes e os voluntários saudáveis foram orientados a manter a rotina alimentar na noite prévia à avaliação. Os pacientes deveriam manter as doses habituais de insulina. Antes do exame, foi aferida a glicemia capilar. Os pacientes com valor $>240 \mathrm{mg} / \mathrm{dl}$ receberam metade da dose de insulina ultrarrápida calculada para correção, conforme prescrição ambulatorial em vigência, com controle glicêmico realizado após a administração da insulina, uma vez que esses valores podem alterar a motilidade gástrica ${ }^{112}$.

No local do abdome em que os eletrodos foram posicionados, a pele foi completamente limpa, sendo utilizada uma lixa para friç̧ão com o objetivo de assegurar que a impedância entre os pares de eletrodos se mantivesse baixa ${ }^{79,113}$.

\subsubsection{Posicionamento dos eletrodos}

Eletrodos de prata/cloreto de prata da MMS (N-00-S) foram posicionados sobre a pele da região do abdome. O eletrodo ground foi posicionado em região de pouco movimento e distante do estômago (próximo ao ombro direito), a cinta respiratória foi fixada em região torácica inferior, e os outros seis eletrodos foram dispostos no mesogástrio da seguinte maneira: o eletrodo 3, utilizado como o principal, foi localizado na linha mediana, no ponto médio entre o processo xifoide e o umbigo; outros dois eletrodos foram localizados em um ângulo superior de 45 graus acima e à esquerda do eletrodo principal (eletrodos 1 e 2); outro eletrodo foi localizado $4 \mathrm{~cm}$ à direita e na mesma linha do eletrodo principal 3 (eletrodo 4); e os eletrodos 5 e 6 foram localizados $2 \mathrm{~cm}$ abaixo do eletrodo principal (eletrodo 3), à esquerda $\mathrm{e}$ à direita, respectivamente ${ }^{86,90}$. A disposição dos eletrodos encontra-se demonstrada na Figura 4. 

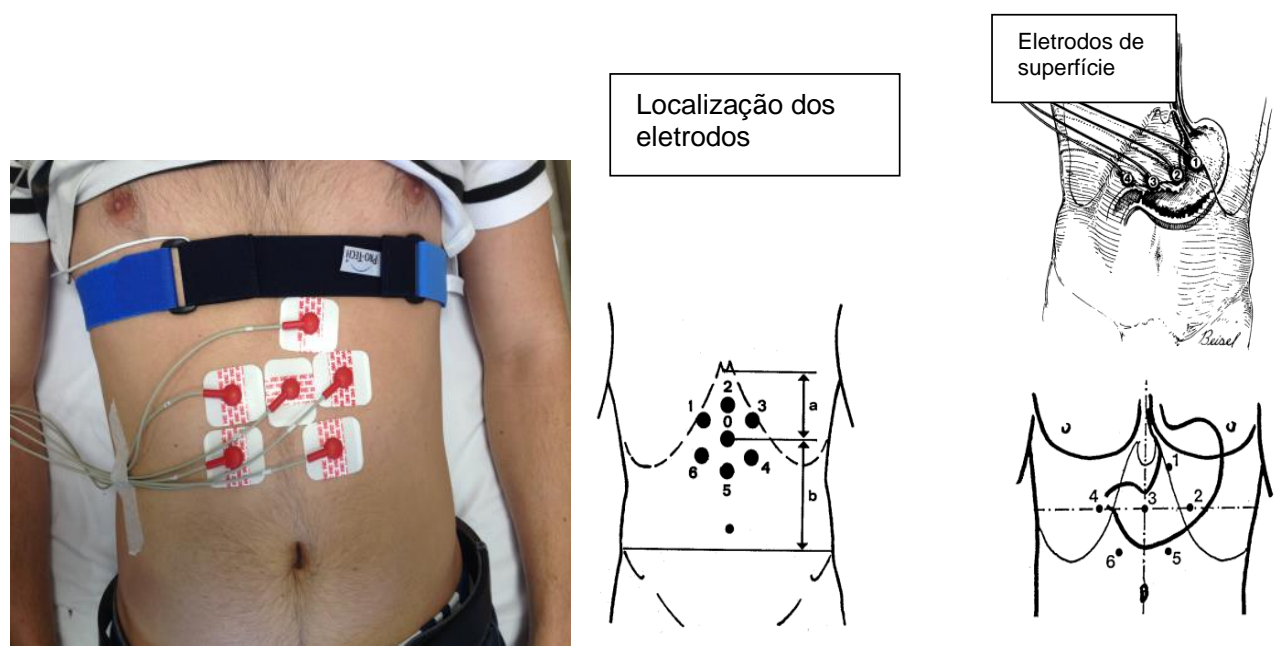

Figura 4 - Posicionamento dos eletrodos

\subsubsection{Posição do indivíduo}

O exame foi realizado com o indivíduo em posição supina e confortável, para que não houvesse movimento do corpo ou o movimento fosse reduzido ao mínimo possível. O indivíduo foi orientado a não se mover, falar, ler ou fazer chamadas telefônicas durante o procedimento, para garantir que a posição fosse a mesma durante todo o estudo. O momento em que houve movimento inevitável do corpo ou movimento dos artefatos foi anotado, e esses períodos foram removidos antes da análise. Durante o estudo, os indivíduos também foram orientados a não dormir ${ }^{74}$.

\subsubsection{Duração do registro}

O registro da EGG foi feito sem gravação durante 10 minutos a 15 minutos, até que o traçado se estabilizasse. O registro foi realizado em dois períodos: o primeiro de 30 minutos, com o paciente em jejum de 8 horas, e o segundo de 30 minutos, após a ingestão de refeição de prova ${ }^{102}$. A refeição de prova foi composta de $20 \mathrm{~g}$ de proteína, $60 \mathrm{~g}$ de carboidrato e $9 \mathrm{~g}$ de gordura, totalizando cerca de $400 \mathrm{kcal}$ (4 torradas, 2 unidades de queijo processado tipo Polenguinho e $250 \mathrm{~g}$ de iogurte whey) ${ }^{74}$. 


\subsubsection{Análise do sinal da eletrogastrografia}

Os dados da EGG foram submetidos a análise visual do registro e a análise computadorizada, com realização de análise espectral de frequências.

\section{Análise visual da eletrogastrografia}

A análise visual foi usada para eliminar artefatos de movimento. Após o final do registro, os sinais captados eram revistos no monitor do computador. Considerou-se artefato de movimento a variação brusca da grande amplitude do sinal, em geral de forma bifásica, associada a movimentos reconhecidos ou supostos. A análise da curva de respiração, detectada por meio da cinta respiratória, também era verificada e os artefatos eram retirados (Figura 5).

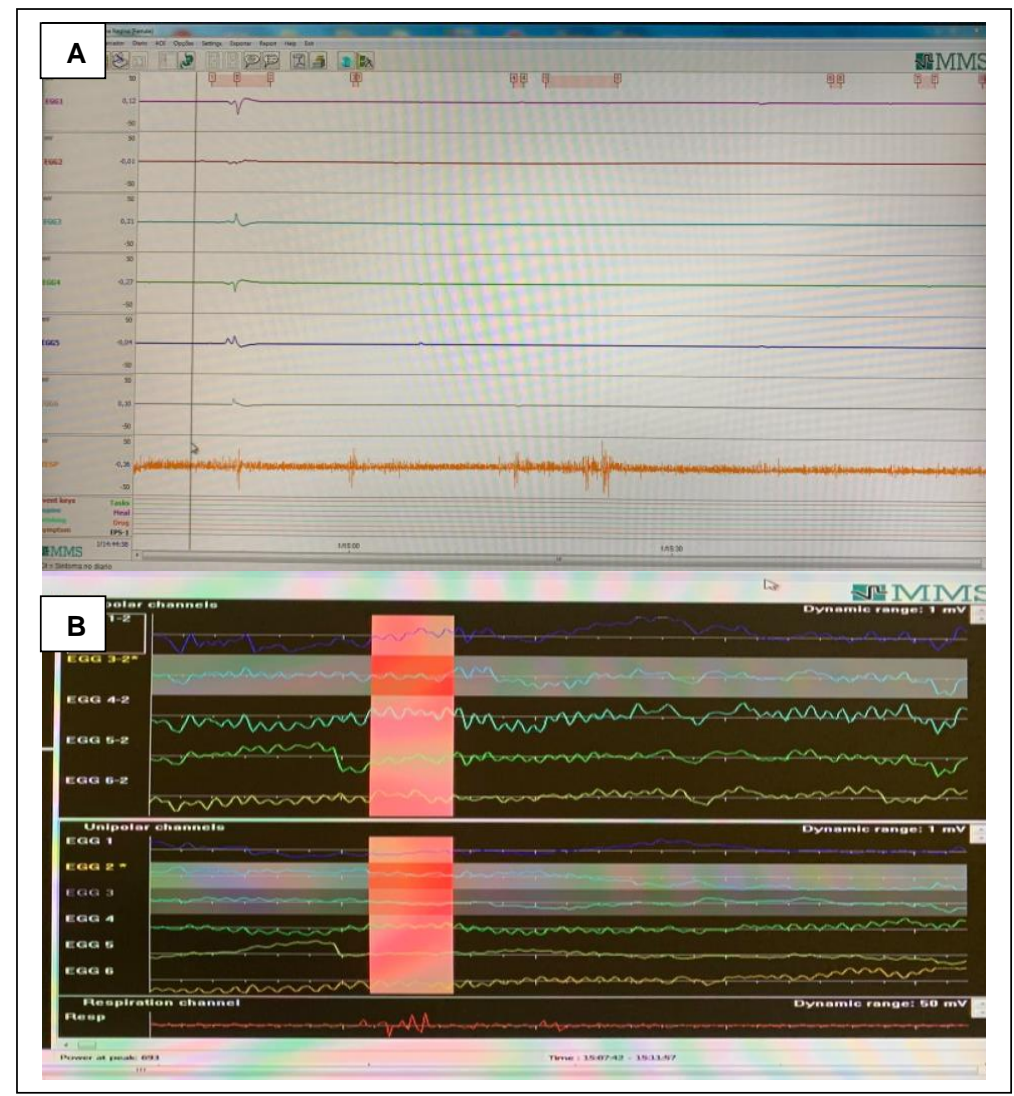

Figura 5 - Em A, análise visual de artefatos, evidenciados na linha laranja inferior, decorrentes de movimento respiratório. Em B, artefato decorrente de movimento respiratório, retirado na análise computadorizada (retângulos em vermelho) 


\section{Análise computadorizada da eletrogastrografia}

Após análise visual e eliminação de artefatos, o registro obtido foi submetido a análise espectral contínua de frequência. $\mathrm{Na}$ análise computadorizada, foram empregadas a FFT e a running spectral analysis ${ }^{114}$. A análise espectral contínua é realizada de maneira que a cada 4 minutos e 15 segundos do registro se construa uma análise espectral. A próxima análise se faz com acréscimo de 1 minuto e assim sucessivamente. A expressão dessas múltiplas análises espectrais parciais ao longo do tempo permite a construção de um gráfico tridimensional com tempo vs. frequência vs. potência dos sinais (Figura 6). As frequências de cada spectrum foram interpretadas por FFT e classificadas da seguinte forma: bradigastria (1-2 $\mathrm{cpm})$, normogastria (2-4 cpm), taquigastria $(4-10 \mathrm{cpm})$ e ritmo duodenal/respiratório $(10-15 \mathrm{cpm})^{74}$.
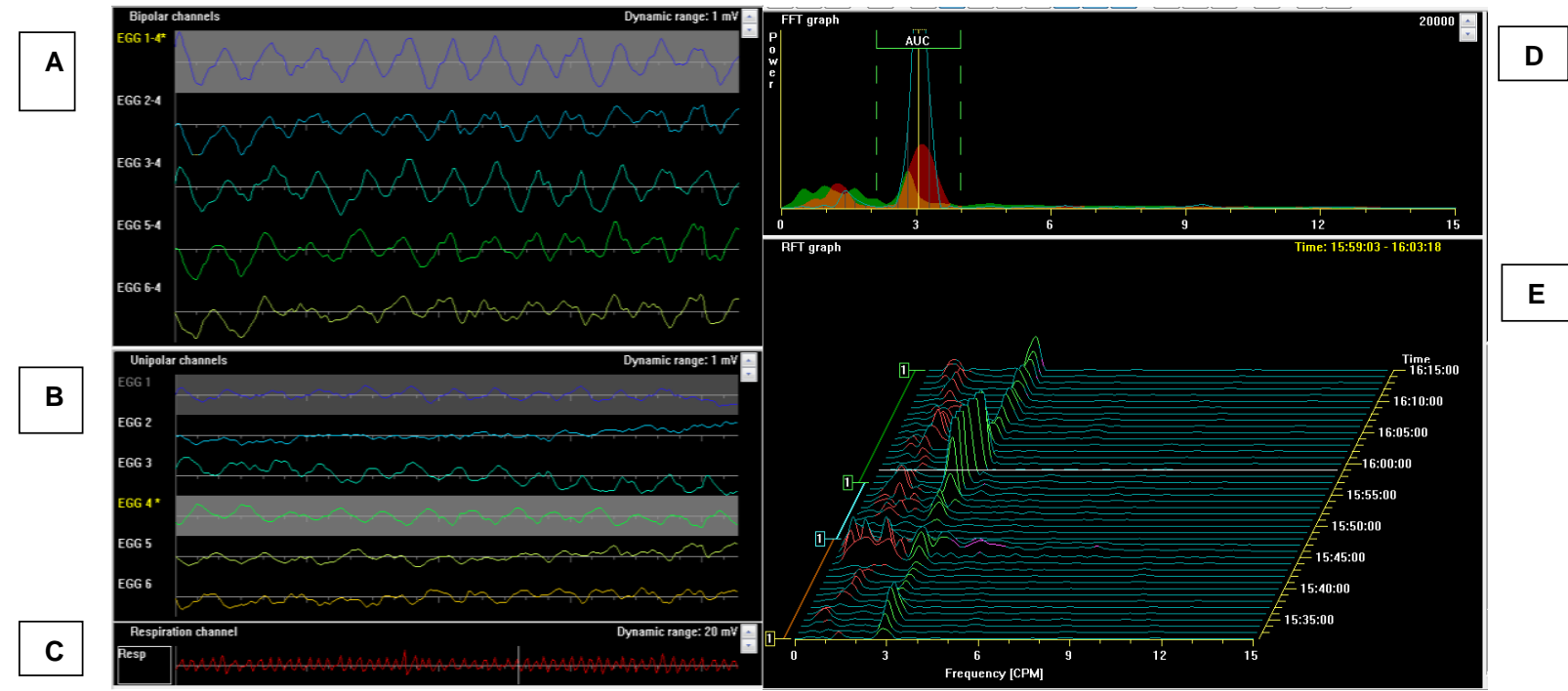

Figura 6 - Análise do sinal da eletrogastrografia multicanal com registro contínuo. Em A, sensores bipolares; em B, sensores unipolares; em $\mathbf{C}$, movimentos respiratórios; em $\mathbf{D}$, transformação rápida de Fourier (FFT); e em E, múltiplas linhas de FFT - análise espectral contínua 
Os seguintes parâmetros derivados da análise computadorizada do sinal da EGG $73,78,115,116$ foram determinados:

1. FD média total nos períodos basal e pós-prandial - A FD é aquela cuja potência do sinal, ocorrendo geralmente em pico, é a maior dentro do espectro. A FD média representa a média das FDs ao longo dos espectros individuais ${ }^{98}$.

2. Porcentagem de tempo da FD em normogastria $(2-4 \mathrm{cpm})$, bradigastria (1-2 cpm), taquigastria (4-10 cpm) e ritmo duodenal/respiratório (10-15 cpm) 74, 117 - Avaliação feita por meio do método de análise espectral contínua, calculando a distribuição da porcentagem nesses intervalos de frequência (normogastria, bradigastria, taquigastria e ritmo duodenal/respiratório) para os períodos basal e pós-prandial.

3. Power ratio (PR) ou variação relativa de potência - Relação da potência dominante, ou seja, valor da potência da FD entre os períodos pós-prandial e basal ${ }^{74}$.

4. Coeficiente de instabilidade $(\mathrm{Cl})$ - Introduzido para definir a variação característica da FD dentro da faixa normal, é calculado como o desvio padrão (DP) dividido pelo valor médio da frequência. Quanto menor o valor do $\mathrm{Cl}$, mais estável é a FD exibida ${ }^{90}$.

\subsubsection{Definição de eletrogastrografia normal}

Considerou-se EGG normal aquela que preenchesse os seguintes critérios:

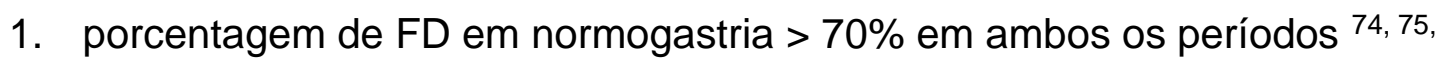
92, 114;

2. variação relativa da potência ou $P R>173,74$.

Os resultados da EGG que não preenchessem esses critérios foram considerados anormais. As anormalidades da EGG consideradas foram as 
alterações do ritmo elétrico gástrico e da resposta à refeição de prova. Os dados das EGGs basal e pós-prandial foram considerados separadamente. A EGG apresentando predomínio de FD fora da faixa de normogastria foi considerada disrítmica, e quando não houve aumento da amplitude na EGG pós-prandial a resposta à refeição de prova foi considerada anormal.

\subsection{Análise Estatística}

O processo de análise de dados da presente pesquisa iniciou-se com uma exploração descritiva. As tabelas incluindo intervalo de confiança de 95\% (IC95\%) foram utilizadas para sumarizar os resultados das variáveis qualitativas. As variáveis quantitativas foram estudadas por meio das estimativas de média, DP, mediana, percentil 25 (P25) e percentil 75 (P75), e mínimos-máximos. Gráficos conjugados de boxplot com histograma auxiliam a visualização da distribuição estatística no grupo controle. O teste de Kolmogorov-Smirnov com correção de Lilliefors foi utilizado para avaliar se as variáveis quantitativas seguiam distribuição normal. Todas as análises levaram em consideração a estratificação, de acordo com o grupo.

A hipótese de que a FD nos períodos basal e pós-prandial tinha a mesma distribuição em ambos os tempos foi testada pelo teste t pareado no grupo controle. Para avaliar a hipótese de que a distribuição das variáveis quantitativas ocorre de forma igual entre o grupo controle, o grupo 1 e o grupo 2, foi aplicado o teste de Kruskal-Wallis de amostras independentes. E para avaliar a diferença entre os grupos no caso de significância, foram utilizadas as comparações múltiplas de Bonferroni. No caso das variáveis qualitativas, o teste exato de Fischer foi usado para análise com a tabela de contingência. Para avaliar a correlação entre as variáveis quantitativas, foi utilizado o coeficiente de correlação de postos de Spearman. 
O poder do teste (1- $\beta$ ) foi calculado para todos os testes de hipótese do estudo. Todas as estatísticas do estudo levaram em consideração um $\alpha$ bidirecional de 0,05 e IC95\% e foram realizadas com apoio computacional dos softwares IBM SPSS 25 (Statistical Package for the Social Sciences) e Excel $2016^{\circledR}$ (Microsoft Office). 
4 RESULTADOS 


\section{RESULTADOS}

Inicialmente, foram avaliados 20 voluntários saudáveis (grupo controle), dos quais 11 (55\%; IC $95 \% 33,8-74,9$ ) eram do sexo feminino e 9 (45,0\%; IC95\% 25,1-66,2), do masculino. A média de idade dos indivíduos investigados foi de 41,0 anos $( \pm 10)$ (Tabela 1$)$.

A FD média basal (repouso) foi de $2,7 \mathrm{cpm}( \pm 0,2)$ e a pós-prandial, de $2,9 \mathrm{cpm}( \pm 0,2)$. A diferença de $0,2 \mathrm{cpm}$ demonstrou ser estatisticamente significante, $\operatorname{com} p=0,010$. Maior detalhamento pode ser visto na Figura 7 .

A FD média demonstrou pouca variabilidade, $2,9 \mathrm{cpm}( \pm 0,3)$, e sua distribuição pode ser visualizada mais detalhadamente na Figura 8. A porcentagem de FD média em normogastria nos períodos basal e pósprandial teve médias de $87,5 \%$ ( $\pm 11,8)$ e $90,4 \%( \pm 9,7)$ e medianas de $87,3 \%$ $(77,0-100,0)$ e $91,5 \% \quad(84,6-100,0)$. Não foi observada diferença estatisticamente significante entre os tempos $(p=0,116)$.

O PR apresentou heterogeneidade entre os indivíduos, com média de $9,5( \pm 15,4)$ e mediana de $3,7(1,9-9,0)$.

Tabela 1 - Análise descritiva das características quantitativas estratificadas no grupo controle, incluindo média, desvio padrão, mediana, intervalo interquartil (P25-P75) e mínimo-máximo

\begin{tabular}{lccc}
\hline & Média $( \pm$ DP) & Mediana (P25-P75) & Mínimo-Máximo \\
\hline Idade, anos & $41,0( \pm 10)$ & $40,0(34,0-48,0)$ & $27,0-68,0$ \\
FD média basal, cpm & $2,7( \pm 0,2)$ & $2,7(2,6-2,9)$ & $2,4-3,1$ \\
FD média pós-prandial, cpm & $2,9( \pm 0,2)$ & $2,9(2,8-3,0)$ & $2,6-3,2$ \\
PR & $9,5( \pm 15,4)$ & $3,7(1,9-9,0)$ & $0,36-67,0$ \\
FD média total, cpm & $2,9( \pm 0,3)$ & $2,8(2,6-3,1)$ & $2,3-3,3$ \\
Normogastria basal, \% & $87,5( \pm 11,8)$ & $87,3(77,0-100,0)$ & $70,5-100,0$ \\
Normogastria pós-prandial, \% & $90,4( \pm 9,7)$ & $91,5(84,6-100,0)$ & $72,2-100,0$ \\
\hline
\end{tabular}

DP - desvio padrão; FD - frequência dominante; P25 - percentil 25; P75 - percentil 75; PR - power ratio. 


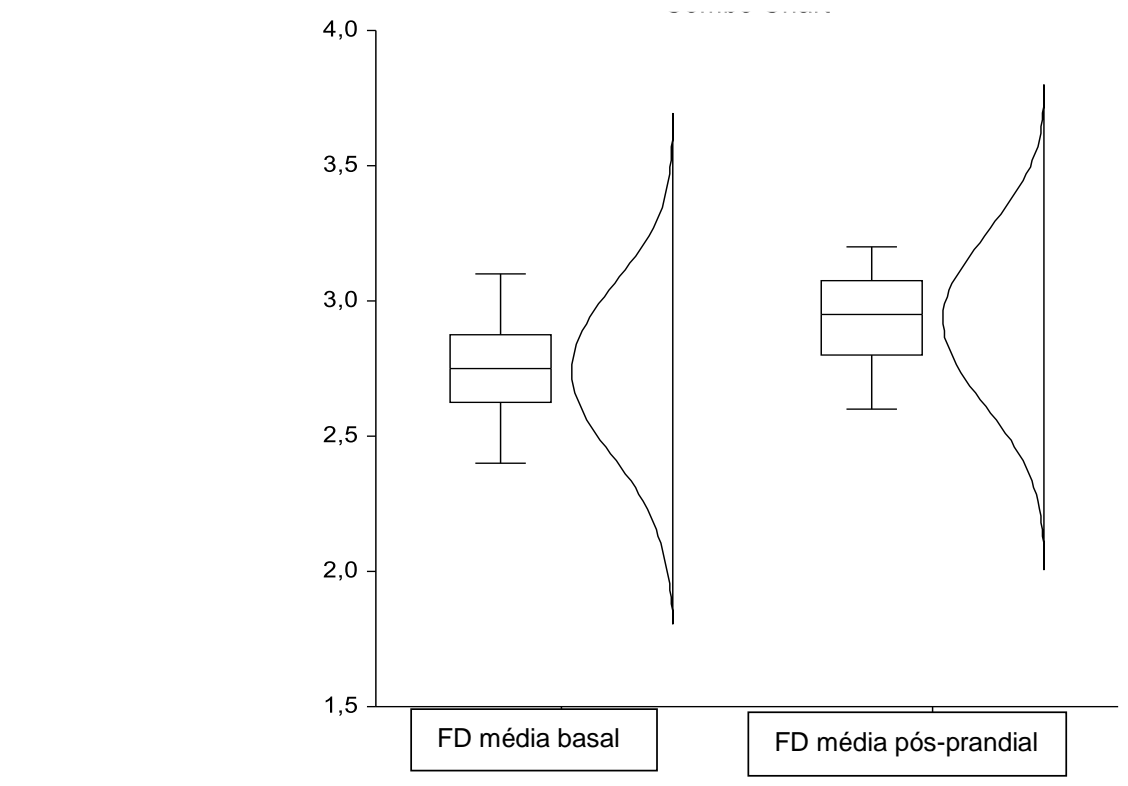

FD - frequência dominante.

Figura 7 - Boxplot e histograma da distribuição das frequências dominantes médias (cpm) basal e pós-prandial

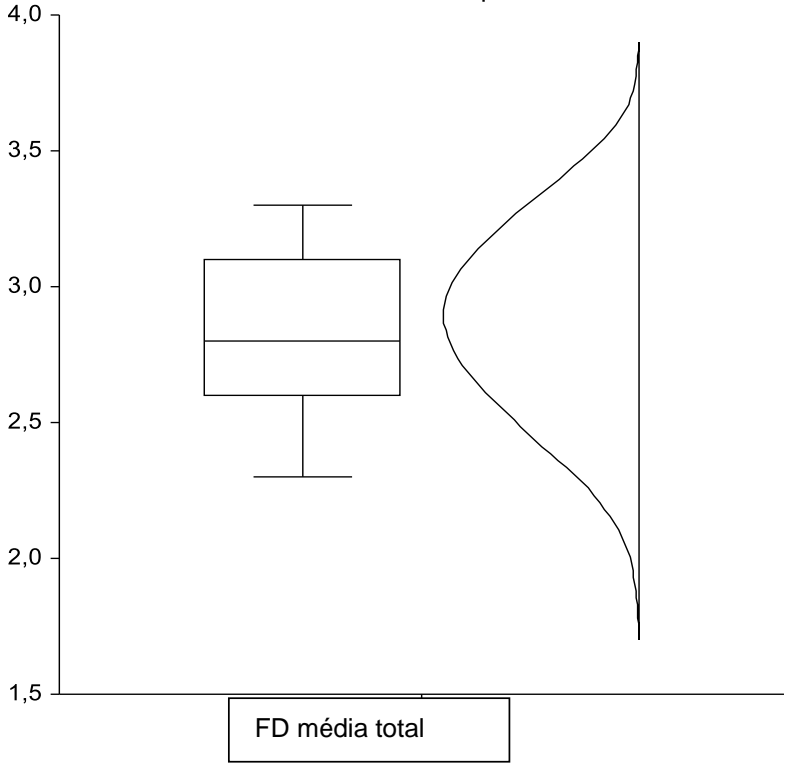

FD - frequência dominante.

Figura 8 - Boxplot e histograma da distribuição da frequência dominante média $(\mathrm{cpm})$ total 
Após a primeira análise dos voluntários saudáveis, os 50 indivíduos selecionados para o estudo foram avaliados, dos quais 20 (40\%) do grupo controle, 15 (30\%) do grupo 1 e 15 (30\%) do grupo 2. Os indivíduos considerados eram, em sua maioria, do sexo feminino (31 indivíduos; 62\%) e apresentavam, no início da avaliação, média de idade de 39,7 anos $( \pm 11,1)$.

Entre as variáveis quantitativas avaliadas, apenas cinco delas apresentaram distribuição normal: idade [média, 40 anos $( \pm 11,1)$ ], FD média basal [média, 2,8 cpm $( \pm 0,2)$ ], FD média pós-prandial [média, 3,0 cpm $( \pm 0,3)$ ], $\mathrm{Cl}$ basal [média, $14,5 \%( \pm 5,4)$ ] e Cl pós-prandial [média, 11,2\% $( \pm 3,5)$ ]. Os demais atributos, apresentados no ANEXO B, demonstram elevada heterogeneidade. Em razão disso, optou-se por um caminho metodológico de emprego das estatísticas não paramétricas nos testes de hipótese que seguem ${ }^{118}$.

A proporção de indivíduos do sexo feminino foi semelhante entre os grupos, sendo 55,0\% (IC95\% 33,8-74,9) no grupo controle, 66,7\% (IC95\% 41,6-86,0) no grupo 1 e 66,7\% (IC95\% 41,6-86,0) no grupo 2, com p = 0,812. Esses dados estão representados na Tabela 2.

Tabela 2 - Análise descritiva das características qualitativas estratificadas de acordo com os grupos, incluindo frequência absoluta, frequência relativa, intervalo de confiança de $95 \%$ e nível descritivo

\begin{tabular}{|c|c|c|c|c|c|c|c|}
\hline \multirow[t]{2}{*}{ Sexo } & \multicolumn{2}{|c|}{$\begin{array}{c}\text { Grupo controle } \\
\text { (voluntários saudáveis) }\end{array}$} & \multicolumn{2}{|c|}{$\begin{array}{c}\text { Grupo } 1 \\
\text { (DM1 sem NAC) }\end{array}$} & \multicolumn{2}{|c|}{$\begin{array}{c}\text { Grupo } 2 \\
\text { (DM1 com NAC) }\end{array}$} & \multirow[t]{2}{*}{$\begin{array}{l}\text { Valor } \\
\text { de } p^{\star}\end{array}$} \\
\hline & $\mathbf{N}$ & \% (IC95\%) & $\mathbf{N}$ & \% (IC95\%) & $\mathbf{N}$ & $\%$ (IC95\%) & \\
\hline Masculino & 9 & $\begin{array}{c}45,0 \\
(25,1-66,2)\end{array}$ & 5 & $\begin{array}{c}33,3 \\
(14,0-58,4)\end{array}$ & 5 & $\begin{array}{c}33,3 \\
(14,0-58,4)\end{array}$ & \multirow{2}{*}{0,812} \\
\hline Feminino & 11 & $\begin{array}{c}55,0 \\
(33,8-74,9)\end{array}$ & 10 & $\begin{array}{c}66,7 \\
(41,6-86,0)\end{array}$ & 10 & $\begin{array}{c}66,7 \\
(41,6-86,0)\end{array}$ & \\
\hline
\end{tabular}

* Baseado no teste exato de Fischer (good-of-fit test $1-\beta=0,805$ )

DM1 - diabetes mellitus tipo 1; IC95\% - intervalo de confiança de 95\%; N - número de indivíduos; NAC - neuropatia autonômica cardiovascular. 
A Figura 9 ilustra a porcentagem de alterações da EGG em relação aos grupos avaliados.

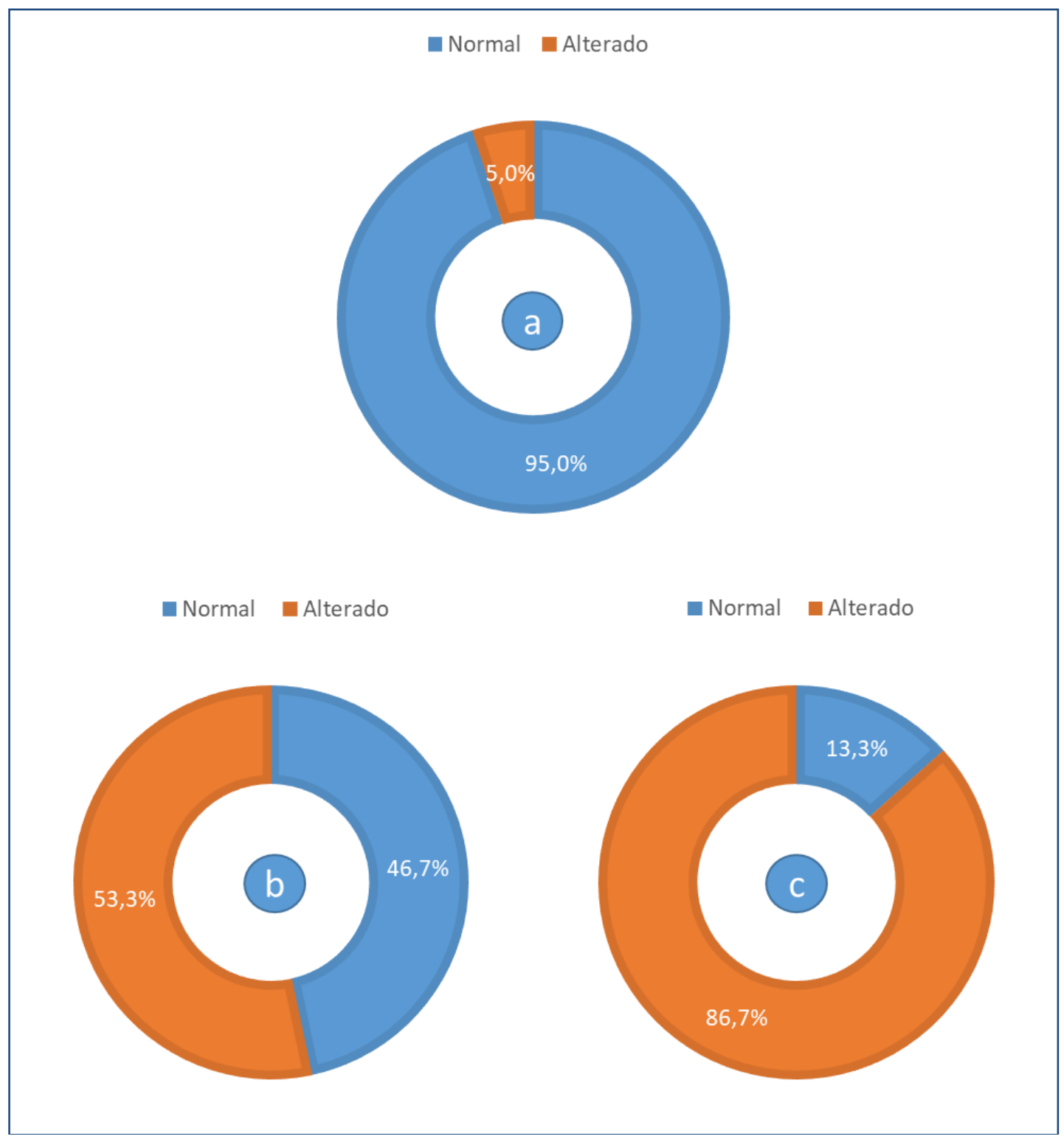

* Valor de $p<0,001$ - teste exato de Fischer (good-of-fit test 1- $\beta=0,900$ ).

DM1 - diabetes mellitus tipo 1; NAC - neuropatia autonômica cardiovascular.

Figura 9 - Porcentagem de alterações da eletrogastrografia em relação aos grupos avaliados: a, grupo controle (voluntários saudáveis); b, grupo 1 (DM1 sem NAC); e c, grupo 2 (DM1 com NAC) 


\section{Padrões dos gráficos da análise espectral contínua de frequência}

No grupo controle, os gráficos da análise espectral foram todos normogástricos (20/20), sendo apenas um com baixa resposta à refeição de prova, evidenciada por $\mathrm{PR}<1,0$ (APÊNDICE C).

Nos grupos 1 e 2, observaram-se gráficos com padrões diversos. Padrão normogástrico, semelhante ao dos controles, foi encontrado em 9 indivíduos (60\%) no basal e em 11 indivíduos (73,3\%) no pós-prandial no grupo 1; no grupo 2, o padrão normogástrico foi encontrado em 7 indivíduos $(46,7 \%)$ no basal e em 9 indivíduos (60\%) no pós-prandial (APÊNDICES D e E). Os demais padrões encontrados nos grupos 1 e 2 foram bradigastria e taquigastria (APÊNDICE G).

Em relação à resposta de refeição de prova avaliada pelo $\mathrm{PR}$, apenas 4 indivíduos do grupo 2 tiveram $\mathrm{PR}>1,0$.

$\mathrm{Na}$ Tabela 3 estão apresentados os dados estatísticos de tendência central e de dispersão para as variáveis quantitativas entre os grupos de interesse. 
Tabela 3 - Análise descritiva das características quantitativas estratificadas de acordo com os grupos, incluindo média, desvio padrão, mediana, intervalo interquartil (P25-P75) e nível descritivo

\begin{tabular}{|c|c|c|c|c|c|c|c|c|}
\hline & \multicolumn{2}{|c|}{$\begin{array}{c}\text { Grupo controle } \\
\text { (voluntários saudáveis) }\end{array}$} & \multicolumn{2}{|c|}{$\begin{array}{c}\text { Grupo } 1 \\
\text { (DM1 sem NAC) }\end{array}$} & \multicolumn{2}{|c|}{$\begin{array}{c}\text { Grupo } 2 \\
\text { (DM1 com NAC) }\end{array}$} & \multirow{2}{*}{$\begin{array}{l}\text { Valor de } \\
\mathbf{p}^{*}\end{array}$} & \multirow{2}{*}{$1-\beta^{* *}$} \\
\hline & $\begin{array}{l}\text { Média } \\
( \pm \text { DP })\end{array}$ & $\begin{array}{l}\text { Mediana } \\
\text { (P25-P75) }\end{array}$ & $\begin{array}{l}\text { Média } \\
( \pm \text { DP })\end{array}$ & $\begin{array}{c}\text { Mediana } \\
\text { (P25-P75) }\end{array}$ & $\begin{array}{l}\text { Média } \\
( \pm \text { DP })\end{array}$ & $\begin{array}{l}\text { Mediana } \\
\text { (P25-P75) }\end{array}$ & & \\
\hline Idade, anos & $41,0( \pm 10,0)$ & $40,0(34,0-48,0)$ & $34,0( \pm 9,0)$ & $33,0(28,0-39,0)$ & $43,0( \pm 13,0)$ & $48,0(32,0-54,0)$ & 0,079 & 0,897 \\
\hline FD média basal, cpm & $2,7( \pm 0,2)$ & $2,7(2,6-2,9)$ & $2,9( \pm 0,2)$ & $2,9(2,8-2,9)$ & $2,8( \pm 0,3)$ & $2,7(2,6-3,0)$ & 0,098 & 0,962 \\
\hline FD média pós-prandial, cpm & $2,9( \pm 0,2)$ & $2,9(2,8-3,0)$ & $3,1( \pm 0,3)$ & $3,1(2,9-3,3)$ & $2,9( \pm 0,3)$ & $2,9(2,6-3,1)$ & 0,134 & 0,912 \\
\hline PR & $13,3( \pm 21,0)$ & $6,0(2,3-14,1)$ & $14,4( \pm 18,9)$ & $7,0(3,8-14,3)$ & $2,9( \pm 7,1)$ & $0,5(0,4-1,0)$ & $<0,001$ & 0,999 \\
\hline FD média total, cpm & $2,9( \pm 0,3)$ & $2,8(2,6-3,1)$ & $3,1( \pm 0,3)$ & $3,1(2,8-3,3)$ & $2,9( \pm 0,4)$ & $3,1(2,6-3,3)$ & 0,048 & 0,960 \\
\hline Normogastria basal, \% & $87,5( \pm 11,8)$ & $87,3(77,0-100,0)$ & $76,0( \pm 23,4)$ & $79,3(60,0-96,3)$ & $70,0( \pm 20,1)$ & $68,4(57,9-85,7)$ & 0,019 & 0,999 \\
\hline Normogastria pós-prandial, \% & $90,4( \pm 9,7)$ & $91,4(84,6-100,0)$ & $77,0( \pm 32,9)$ & $100,0(58,3-100,0)$ & $78,0( \pm 17,1)$ & $79,3(62,5-93,1)$ & 0,138 & 0,900 \\
\hline Bradigastria basal, \% & $9,1( \pm 9,0)$ & $10,8(0,0-14,8)$ & $10,3( \pm 11,4)$ & $5,6(0,0-17,9)$ & $21,4( \pm 15,9)$ & $20,0(14,3-27,3)$ & 0,014 & 0,999 \\
\hline Bradigastria pós-prandial, \% & $4,7( \pm 7,7)$ & $0,0(0,0-9,3)$ & $3,5( \pm 8,3)$ & $0,0(0,0-0,0)$ & $12,3( \pm 16,7)$ & $4,2(0,0-20,8)$ & 0,052 & 0,790 \\
\hline Taquigastria basal, \% & $2,0( \pm 3,8)$ & $0,0(0,0-2,7)$ & $13,7( \pm 19,9)$ & $11,1(0,0-13,9)$ & $8,9( \pm 11,3)$ & $7,4(0,0-15,0)$ & 0,005 & 0,999 \\
\hline Taquigastria pós-prandial, \% & $3,1( \pm 4,8)$ & $0,0(0,0-6,8)$ & $19,5( \pm 32,9)$ & $0,0(0,0-23,8)$ & $9,7( \pm 11,1)$ & $8,0(0,0-17,2)$ & 0,179 & 0,899 \\
\hline
\end{tabular}

* Baseado no teste Krustal-Wallis de amostras independentes.

** Baseado em testes da família F.

DM1 - diabetes mellitus tipo 1; DP - desvio padrão; FD - frequência dominante; NAC - neuropatia autonômica cardiovascular; P25 - percentil 25; P75 - percentil 75; PR - power ratio. 
Na Figura 10 (A a E) é possível verificar as comparações múltiplas, entre os grupos avaliados, em relação a PR, porcentagem de normogastria e FD média total. O quadro geral está apresentado no ANEXO F.

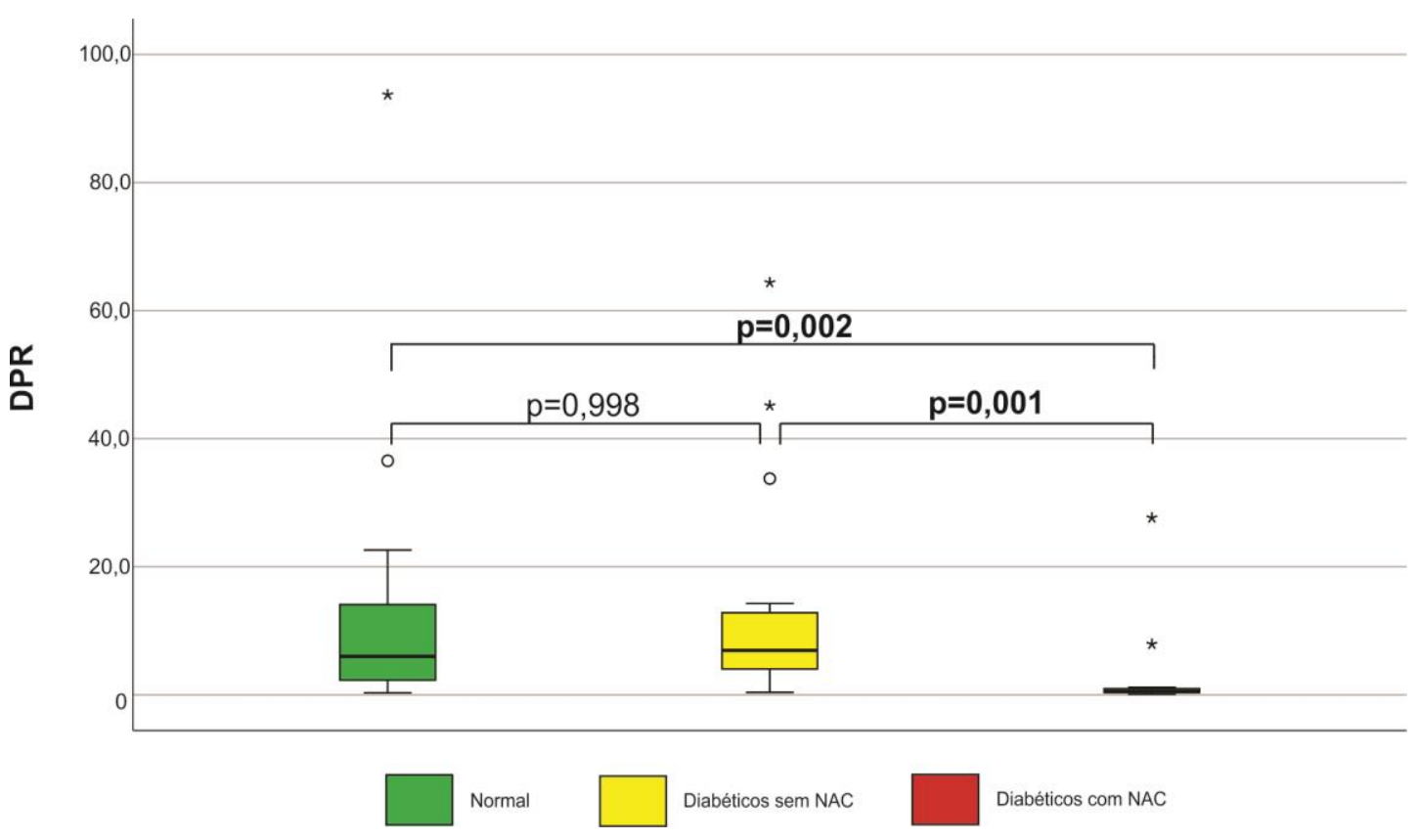

NAC - neuropatia autonômica cardiovascular.

Figura 10A - Comparação do power ratio (PR) entre os grupos de indivíduos normais; de pacientes diabéticos sem NAC; e de pacientes diabéticos com NAC 


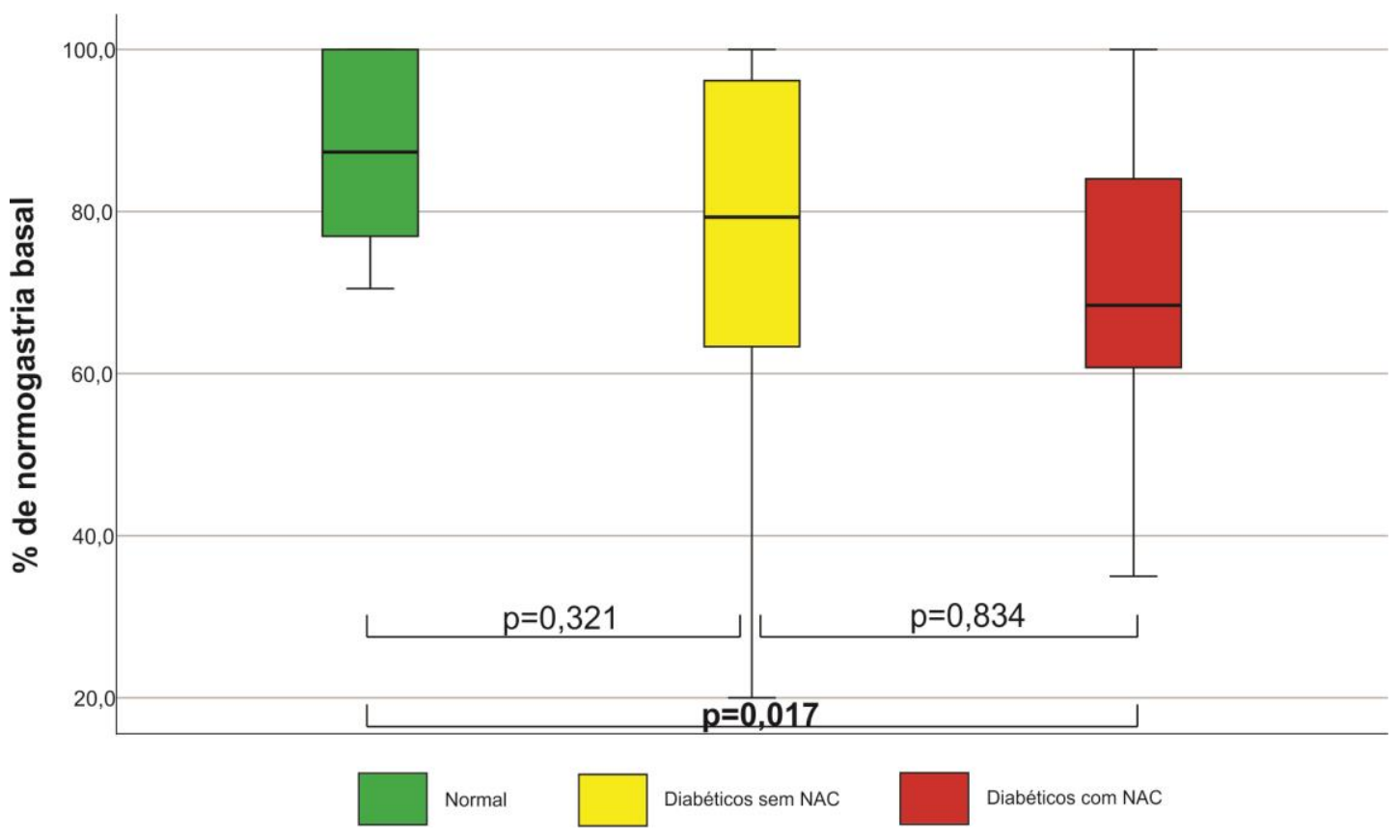

NAC - neuropatia autonômica cardiovascular.

Figura 10B - Comparação da porcentagem de normogastria basal entre os grupos de indivíduos normais; de pacientes diabéticos sem NAC e de pacientes diabéticos com NAC 


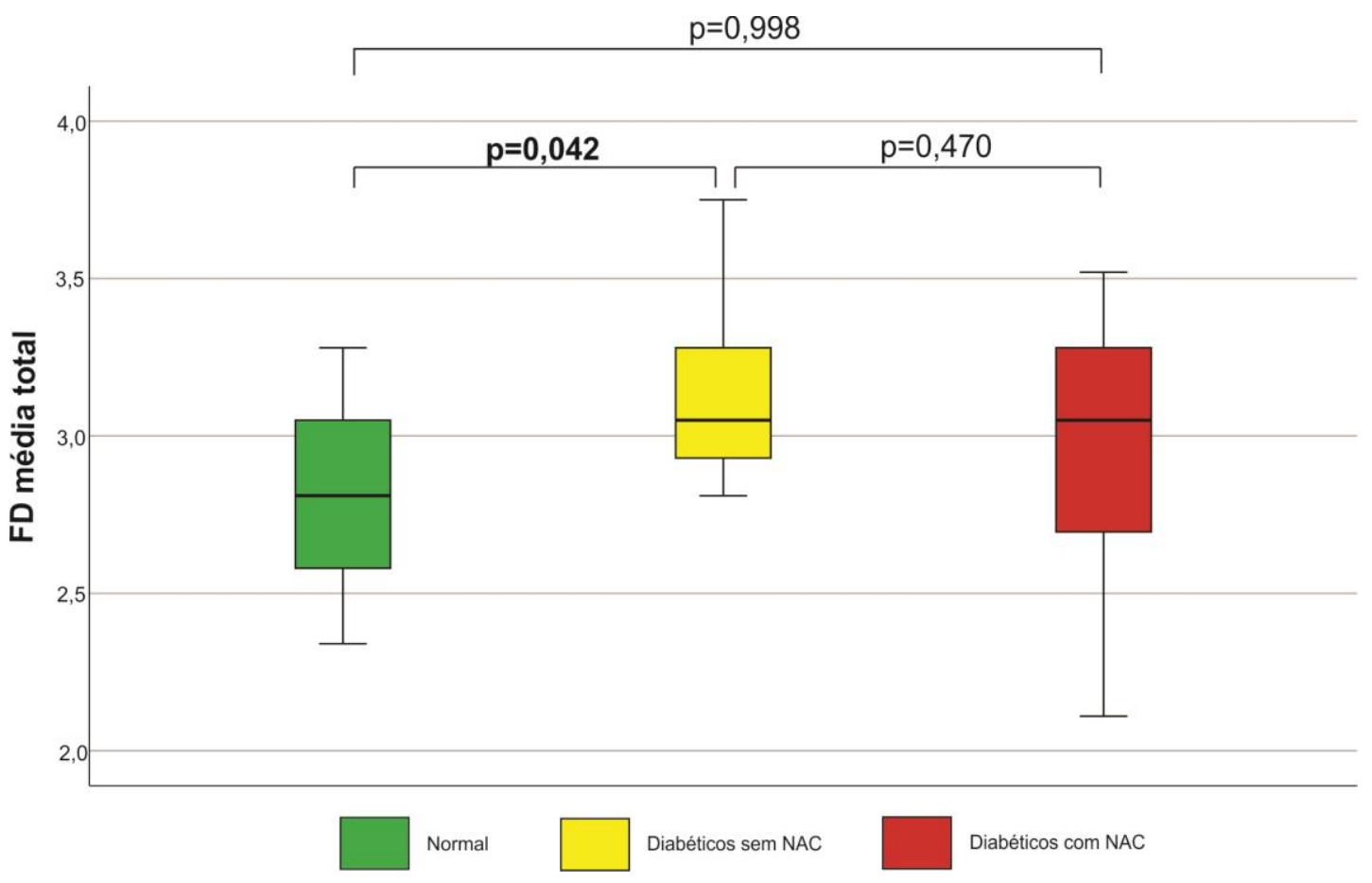

NAC - neuropatia autonômica cardiovascular.

Figura 10C - Comparação da frequência dominante (FD) média total entre os grupos de indivíduos normais; de pacientes diabéticos sem NAC e de pacientes diabéticos com NAC 


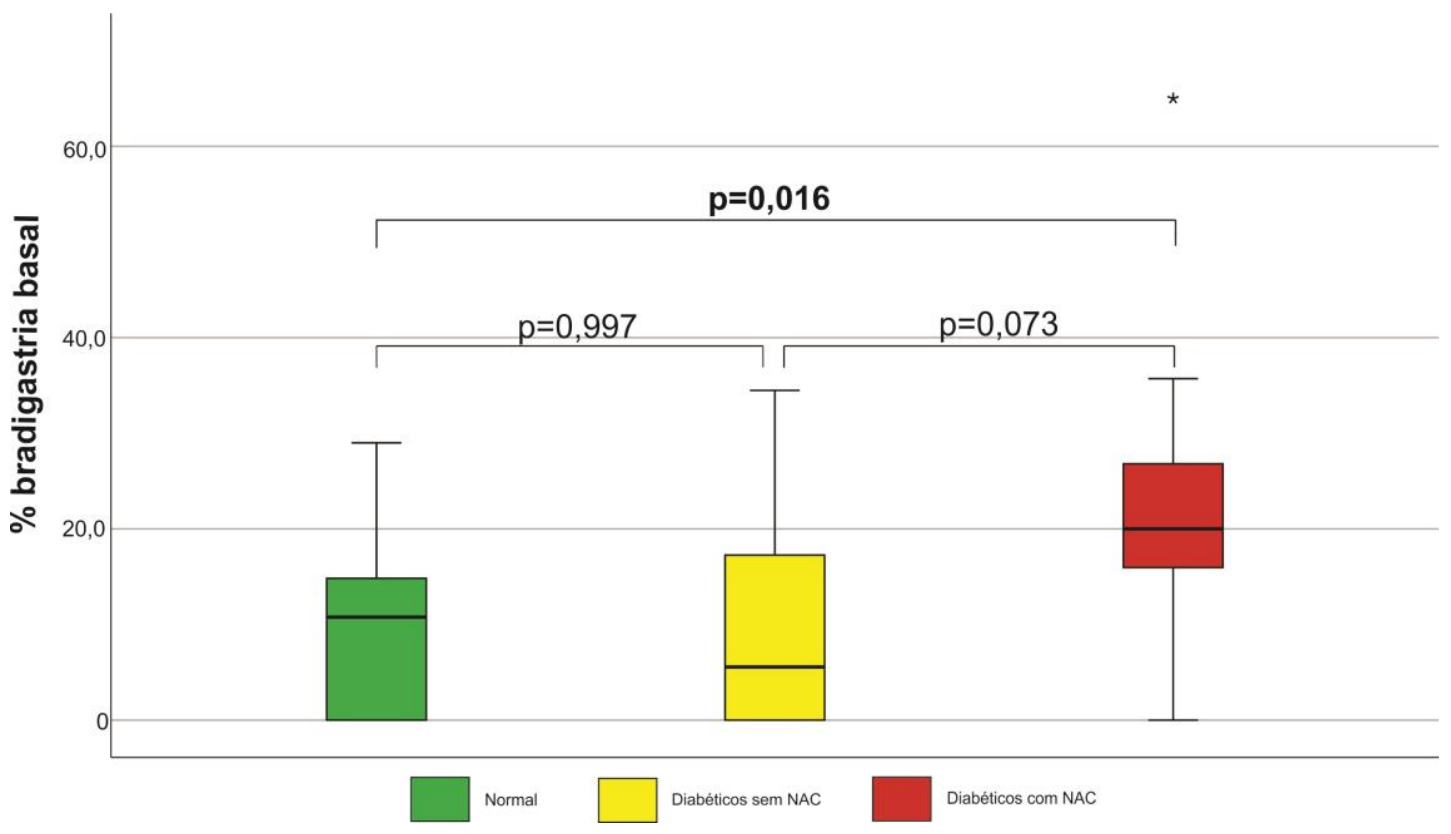

NAC - neuropatia autonômica cardiovascular.

Figura 10D- Comparação da porcentagem de bradigastria basal entre os grupos de indivíduos normais; de pacientes diabéticos sem NAC e de pacientes diabéticos com NAC 


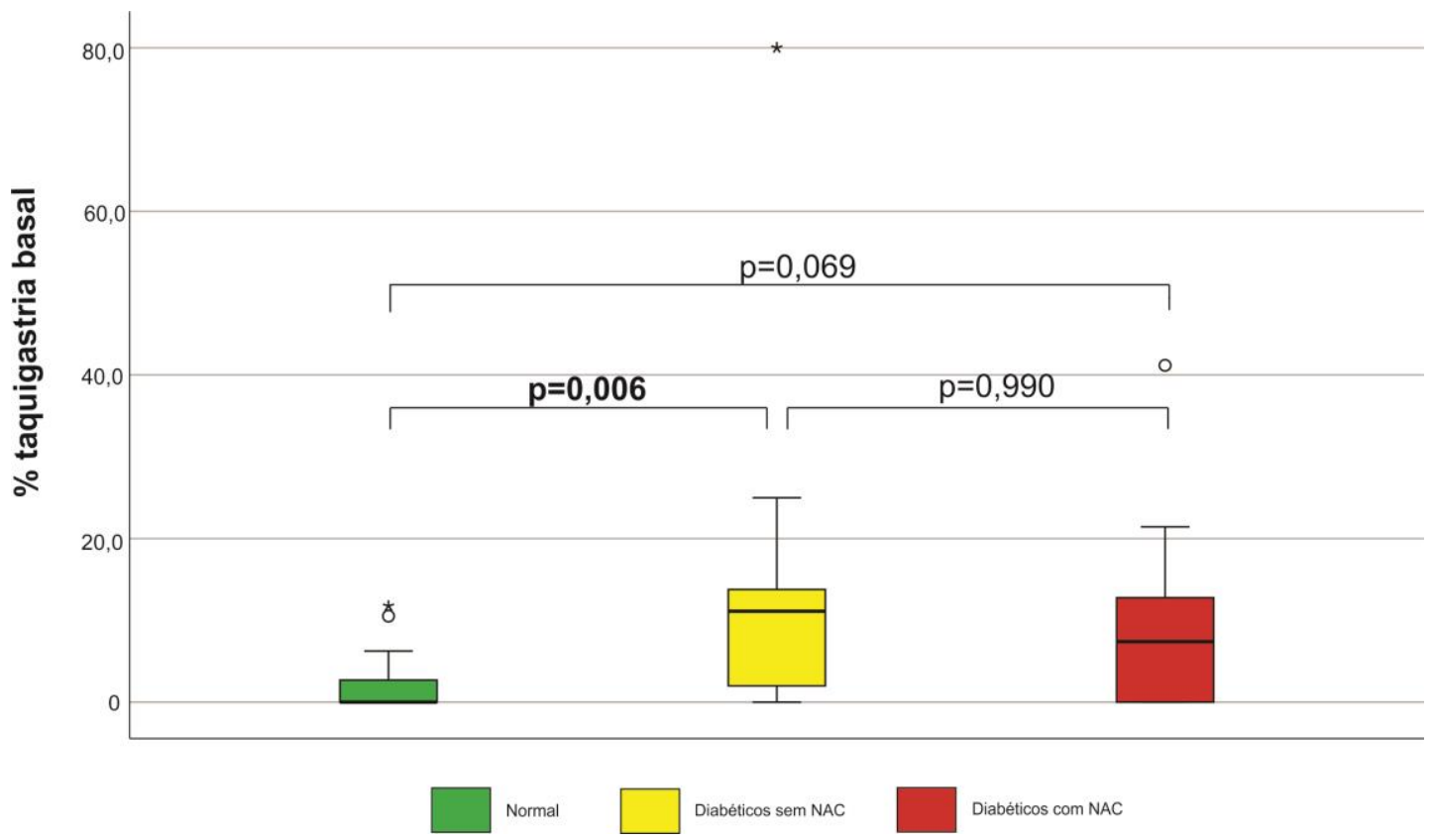

NAC - neuropatia autonômica cardiovascular.

Figura 10E - Comparação da porcentagem de taquigastria basal entre os grupos de indivíduos normais; de pacientes diabéticos sem NAC e de pacientes diabéticos com NAC 
Uma análise de correlação entre o total de sintomas e os resultados da EGG foi realizada no grupo 2. Os parâmetros de normogastria basal e de normogastria pós-prandial mostraram-se inversamente correlacionados, ou seja, quanto maior o índice de sintomas menor a porcentagem de normogastria basal e pós-prandial e quanto menor o índice de sintomas maior a porcentagem de normogastria basal e pós-prandial. O parâmetro PR, embora tenha apresentado correlação negativa, não esteve significativamente associado (Tabela 4).

Tabela 4 - Análise de correlação, realizada no grupo 2, entre o total de sintomas e os parâmetros de normogastria basal, normogastria pós-prandial e PR, incluindo coeficiente de correlação, valor de p e número de indivíduos considerados

\begin{tabular}{lccc}
\hline Total de sintomas & Normogastria basal & $\begin{array}{c}\text { Normogastria pós-prandial } \\
\%\end{array}$ & PR \\
\hline Coeficiente de correlação & $-0,637$ & $-0,666$ & $-0,140$ \\
Valor de $p$ & 0,011 & 0,007 & 0,620 \\
$1-\beta^{*}$ & 0,999 & 0,999 & 0,730 \\
$\mathrm{~N}$ & 15 & 15 & 15 \\
\hline
\end{tabular}

* Baseado na estatística de correlação.

$\mathrm{N}$ - número de indivíduos; PR - power ratio. 
5 DISCUSSÃO 


\section{DISCUSSÃO}

Com o desenvolvimento tecnológico ao longo dos anos, o modo como a EGG passou a ser registrada e as novas configurações vêm tornando o teste mais confiável. As dificuldades de captação de sinais de baixa amplitude e a suscetibilidade de artefatos, por exemplo, são cada vez menores, de acordo com os avanços da tecnologia empregada nessa técnica e à medida que novos profissionais possam ter conhecimento do método $68,115,119$.

Este estudo avaliou a atividade mioelétrica gástrica em voluntários saudáveis (grupo controle) e em pacientes com DM1 sem NAC (grupo 1) e com NAC (grupo 2) e demonstrou que os pacientes com DM1 com e sem NAC podem apresentar distúrbios da atividade miolétrica gástrica. A prevalência de disritmias gástricas é maior em pacientes com DM1 com NAC, retardo do esvaziamento gástrico e sintomas de gastroparesia, comparativamente a pacientes sem NAC e sem sintomas de gastroparesia e a indivíduos voluntários saudáveis.

Trata-se do primeiro estudo empregando a EGG multicanal em nosso meio. A utilização de um equipamento com novas configurações, amplificadores e filtros, eletrodos de caráter bipolar e maior variedade de canais tornou mais fácil a escolha do melhor sinal entre todos os registros para representar a melhor medida da atividade mioelétrica gástrica ${ }^{89}$. Estudos demonstram que a obtenção de dados por meio de EGG multicanal pode evidenciar maiores informações da atividade mioelétrica gástrica em pacientes com suspeita de desordens de motilidade, náusea e vômitos inexplicáveis, gastroparesia e outros sintomas dispépticos $86,87,90$.

A distribuição dos grupos em relação ao sexo em nosso estudo aconteceu de forma homogênea. Estudos com voluntários saudáveis demonstram que não há diferença no resultado da EGG de acordo com o sexo 98. No presente estudo, observou-se que, avaliando isoladamente o grupo 
controle, também não houve diferença nos resultados da EGG em relação ao sexo.

Em relação à faixa etária, foi evidenciada distribuição homogênea entre os grupos, com média de 40 anos $( \pm 11,1)$ (Apêndice B). Não há evidências, na literatura, de alterações na EGG entre voluntários saudáveis na faixa etária variando de 18 anos a 60 anos 85,86 .

Os resultados obtidos no grupo controle apresentaram ao exame de EGG uma variação da FD média total de 2,3-3,3 cpm (Tabela 1), sendo essa

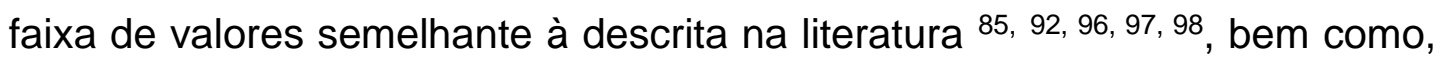
nos períodos basal e pós-prandial os resultados também ficaram em conformidade com a literatura variando de 2,0-4,0 com 87, 96, 98. Em nosso meio, em outro estudo, a variação da FD média total no basal foi de 1,17-3,05 com, porém neste estudo ${ }^{9}$, os exames foram realizados com aparelho de EGG com apenas um canal, diferente do utilizado no presente estudo, em que se empregou o aparelho multicanal sendo fator crucial para a diferença obtida.

$\mathrm{Na}$ análise da EGG, ainda no grupo controle, observou-se alta porcentagem da FD média em normogastria, de $87,5 \%$ e $90,4 \%$ nos períodos basal e pós-prandial, respectivamente, permanecendo $>70 \%$ em ambos os períodos (Tabela 1), valores semelhantes aos da literatura $74,98,117$. Com estes dados sugerimos que a porcentagem da FD em normogastria deveria ser > $80 \%$ ou até $85 \%$ em ambos os períodos (basal e pós-prandial) e não > $70 \%$ segundo a literatura.

Outro dado obtido com a EGG é o PR e este quando $<1$ pode evidenciar uma resposta insatisfatória motora do estômago ao estímulo dado e quando $>1$ determina resposta satisfatória $74,76,98,114$. Em nosso estudo, apenas um indivíduo do grupo controle apresentou $P R<1$, ou seja, não apresentou resposta positiva à refeição de prova enquanto todos os outros 19 indivíduos apresentaram PR $>1$ (Figura 9).

Os grupos de pacientes com DM1 estudados, foram escolhidos por ser a NAC a manifestação mais bem descrita da NAD e por ser conhecido que a 
NAD pode afetar o SNA, levando a alteração do sistema nervoso entérico e, consequentemente, a distúrbios da atividade mioelétrica gástrica ${ }^{9,10}$.

Os dados encontrados no atual estudo estão de acordo com os de Kawagishi et al. ${ }^{120}$, que da mesma forma demonstraram que pacientes com NA têm maior prevalência de distúrbios da atividade mioelétrica gástrica, quando comparados a pacientes diabéticos sem NA ${ }^{120}$, no entanto, a gastroparesia diabética no grupo com NA não foi confirmada por esvaziamento gástrico por cintilografia e, além disso, não foi utilizada EGG multicanal diferenciando em ambos os aspectos do nosso estudo.

A avaliação dos traçados eletrogastrográficos dos dois grupos de pacientes com DM1 e a comparação com o grupo controle de voluntários saudáveis demonstrou diferenças entre os grupos que podem estar correlacionadas a NA e a retardo do esvaziamento gástrico.

Este estudo demonstrou que pacientes com DM1, com ou sem NAC, podem apresentar distúrbios da atividade mioelétrica gástrica havendo maior prevalência de disritmias gástricas nos pacientes do grupo 2. Não obstante, alguns autores demonstram que há associação entre parâmetros de disritmia ao exame de EGG e gastroparesia ${ }^{68,99}$; maior prevalência de anormalidades na EGG comparados a voluntários saudáveis ${ }^{114}$ e em pacientes com NAC e retardo no esvaziamento gástrico há menor porcentagem de ondas lentas dentro da normalidade 93, 114. Mais recentemente, um estudo sugeriu a associação entre a redução da função do SNS durante o período de repouso e o retardo do esvaziamento gástrico sendo que esta associação está relacionada ao DM e não a um marcador independente do retardo do esvaziamento gástrico, segundo os autores ${ }^{121}$.

No nosso estudo observou-se EGG anormal em 5\% dos indivíduos do grupo controle, em $53,3 \%$ dos pacientes do grupo 1 e em $86,7 \%$ dos pacientes do grupo 2 sugerindo que a NAC, manifestação mais comum da NAD, pode estar mais frequentemente relacionada a alterações da atividade mioelétrica gástrica do que nos pacientes sem NAC e voluntários saudáveis. Assim, esta diferença de 33,4\% (53,3\% - 86,7\%) poderia ser indicativo de evolução desses 
pacientes para a NAC ou até podemos conjecturar que a EGG alterada possa indicar maior risco de desenvolvimento de NAC ou mesmo representar sinal precoce de NAD. Estudos longitudinais futuros em seguimento desses pacientes poderiam esclarecer melhor esta hipótese. Neste estudo, demonstrou-se também que nos grupos de pacientes com DM1 foram encontrados distúrbios da atividade mioelétrica gástrica evidenciados na EGG e que as disritmias gástricas constituem uma das alterações da gastroparesia diabética, podendo também haver diferenças significantes entre pacientes com DM1 com NAC e retardo do esvaziamento gástrico e pacientes com DM1 sem NAC, de acordo com os parâmetros utilizados (Tabela 3).

Ao se avaliar os parâmetros separadamente (Tabela 3), percebe-se que, em relação à porcentagem de normogastria basal (repouso), houve diferença significante entre os grupos, apresentando a seguinte variação: grupo controle, 77,0-100,0; grupo 1, 60,0-96,3; e grupo 2, 57,9-85,7 ( $p=$ $0,019)$. A partir de comparações múltiplas com essa variável, observou-se $p=$ 0,017 entre o grupo controle e o grupo 2 (Figura 10B). Esse parâmetro teve valor significativo na correlação entre os grupos no período basal (repouso), mas não apresentou valores significativos no período pós-prandial.

Os episódios de disritmia gástrica nos pacientes dos grupos com DM1 foram mais frequentes durante o período interdigestivo ( $E G G$ basal), considerando que a porcentagem de normogastria foi significativamente menor nesse período em relação ao período pós-prandial, estando de acordo com outros estudos na literatura, cujos achados demonstram que os episódios de disritmia gástrica são mais prevalentes no período interdigestivo ${ }^{18}$.

Os períodos de bradigastria avaliados por meio da porcentagem de bradigastria evidenciaram diferenças entre os grupos e demonstraram que os pacientes do grupo 2 apresentaram porcentagem de bradigastria maior que a dos outros dois grupos (grupo 1 e grupo controle) (Figura 10D). Portanto, pacientes que apresentam NAC instalada e retardo do esvaziamento gástrico têm maior prevalência de disritmia gástrica. 
Em relação a variação relativa da potência dominante entre os períodos pós-prandial e basal (PR), também houve diferença estatística entre os grupos (Tabela 3). No grupo controle, obteve-se mediana de 6,0; no grupo 1, a mediana foi de 7,0; e no grupo 2, a mediana foi de 0,5 ( $p<0,001$ ). Em uma comparação múltipla para esse fator $\mathrm{PR}$, diferenças foram observadas entre o grupo controle e o grupo $2(p=0,002)$ (Figura 10A). Esse achado sugere que pacientes com DM1 com NAC e gastroparesia apresentam menor ocorrência de potenciais de ação, resultando em menor atividade contrátil em resposta à ingestão de alimentos. Da mesma forma, no estudo de Chen et al. 93, o PR em pacientes com retardo do esvaziamento gástrico também não demonstrou aumento relativo da potência no pós-prandial comparados aos voluntários saudáveis ${ }^{93}$. Fortes evidências sugerem associação do aumento da amplitude ou potência da EGG no período pós-prandial com a presença de contrações gástricas efetivas em voluntários saudáveis ${ }^{74}$.

A gastroparesia diabética pode apresentar um largo espectro de manifestações clínicas, sendo os sintomas atribuídos à gastroparesia relatados entre $5 \%$ e $12 \%$ dos pacientes com $\mathrm{DM}^{31}$. Os principais sintomas são náusea, vômito pós-prandial, saciedade precoce, sensação de plenitude na região epigástrica e dor epigástrica ${ }^{24,48,122}$. Estudos demonstram que a relação entre a melhora dos sintomas e a normalização do esvaziamento gástrico por cintilografia é fraca, e isso se deve aos mecanismos patogênicos heterogêneos dos sintomas na gastroparesia ${ }^{123,124}$. Muitos pacientes com diabetes e esvaziamento gástrico alterado podem ter poucos sintomas, e outros pacientes com muitos sintomas podem ter esvaziamento gástrico normal 39. Diversas anormalidades, incluindo acomodação gástrica, sensibilidade à distensão, disfunção da inervação aferente e distúrbios da atividade mioelétrica gástrica podem contribuir para os sintomas ${ }^{125}$.

Em um estudo recente, não foi encontrado nenhuma diferença no PAGI-SYM, GCSI ou qualquer uma de suas subdivisões entre pacientes com esvaziamento gástrico normal e retardado. Essa falta de associação entre esvaziamento gástrico e sintomas relatados pelos pacientes é um dos principais desafios no campo da pesquisa em gastroparesia e esse fato é de 
provável causa multifatorial. Os pacientes com suspeita de gastroparesia diabética podem apresentar uma diversidade de sintomas inespecíficos e, além disso, o esvaziamento gástrico retardado está presente em 30\%-50\% dos diabéticos de longa data, independente dos sintomas, provavelmente como consequência da neuropatia autonômica. Uma outra questão, é a gastroparesia diabética estar associada a múltiplas alterações fisiopatológicas, tanto diretamente no intestino como no sistema autônomo e central. Algumas dessas alterações, com a perda intersticial de Cajal, podem ser diretamente ligadas ao desenvolvimento de EG retardado ${ }^{126}$.

No entanto, há evidências de associação entre distúrbios da atividade mioelétrica gástrica revelados pela EGG e relato de sintomas dispépticos crônicos, como náusea, plenitude pós-prandial e saciedade precoce 99, 107, 127. O sintoma que mais se correlaciona com distúrbios da atividade mioelétrica gástrica e esvaziamento gástrico é a presença de náusea em pacientes

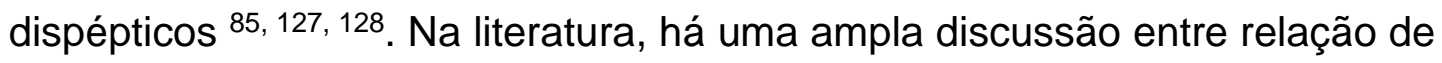
sintomas do TGI superior e alteração da atividade mioelétrica gástrica e esvaziamento gástrico. Em um estudo de Gharibans et al. ${ }^{129}$ foi evidenciado correlação entre a intensidade dos sintomas pelo GCSI e o percentual de alterações na propagação da onda lenta em pacientes com gastroparesia avaliados por EGG de alta resolução, mostrando que há uma possível contribuição da disfunção da atividade miolétrica gástrica em relação a gênese dos sintomas na gastroparesia ${ }^{129}$. Dessa forma, analisar a relação da atividade mioelétrica gástrica com sintomas de pacientes com gastroparesia diabética e retardo do esvaziamento gástrico pode contribuir para melhor entendimento da doença.

Os pacientes do grupo 2 foram avaliados, em relação ao total de sintomas apresentados, pelo GCSI-adaptado, aonde demostrou-se que houve correlação inversa com significância estatística nos parâmetros de porcentagem de normogastria nos períodos basal e pós-prandial, ou seja, quanto maior a pontuação de sintomas apresentados pelo GCSI-adaptado menor a porcentagem de normogastria. Por outro lado, o PR apesar de ser um parâmetro que se mostrou significativamente positivo para DM1 com NAC 
na comparação entre os grupos, não teve correlação com a pontuação de sintomas de gastroparesia. Assim, a porcentagem de normogastria da FD média nos períodos basal e pós-prandial parece ser um bom parâmetro que se associa com os sintomas de pacientes com gastroparesia diabética com NAC (Tabela 4).

A literatura é controversa em relação aos sintomas e a gastroparesia, pois Pasricha et al. ${ }^{130}$ não evidenciaram relação entre o total de sintomas pelo GCSI e o retardo do esvaziamento gástrico, e um outro estudo, Goucerol et al. ${ }^{131}$ demonstraram que a estimulação elétrica gástrica foi eficaz em melhorar os sintomas mas não o esvaziamento gástrico. Dessa forma, a atividade elétrica gástrica parece estar mais relacionada aos sintomas do que o próprio EG e portanto a EGG pode ser considerada um melhor marcador correlacionado aos sintomas dos pacientes ${ }^{130,131}$.

Há algumas limitações em nosso estudo. Outras condições poderiam determinar maior prevalência de disritmia gástrica, tais como: as lesões estruturais das $\mathrm{CICs}$, hiperglicemia e uremia ${ }^{24}$. A hiperglicemia e a uremia foram avaliadas e controladas ou excluídas deste estudo. Portanto, a variabilidade de alterações encontradas nos grupos de pacientes DM1 com e sem NAC poderia ser em razão dessa outra condição de lesão estrutural das CICs, visto que $53,3 \%$ dos pacientes sem NAC tiveram alterações na EGG. A possibilidade de que lesões da rede de CICs que ocorrem nos pacientes com DM possam justificar as alterações da EGG, mesmo antes de surgir sinais de acometimento do SNA que modula a atividade dessa rede de células, deve ser considerada. Estudos histopatológicos em pacientes com gastroparesia diabética demonstraram alteração da inervação autonômica, com diminuição de fibras simpáticas e alterações vagais, do mesmo modo, demonstraram perda de integridade da rede de CICs. Algumas evidências experimentais fundamentam a modulação neural sobre o potencial de marca-passo gástrico e a participação de lesões neuronais na gênese de distúrbios da atividade gástrica 7,132 . Neste estudo, não foi avaliado o histopatológico desses pacientes, portanto não se avaliou diretamente a integridade das CICs. 
Em conclusão, nossos achados demonstram que a EGG, método não invasivo e isento de radiação, é capaz de identificar alterações mioelétricas gástricas na gastroparesia diabética e NAC. Novos conhecimentos a respeito de arritmia gástrica estão evoluindo rapidamente em razão de recentes avanços em tecnologias. O principal desafio agora é tentar traduzir esse conhecimento em métodos clínicos mais aprimorados para testar a atividade mioelétrica gástrica ${ }^{68}$. 


\section{CONCLUSÕES}




\section{CONCLUSÕES}

Com base nos resultados apresentados neste estudo, pôde-se concluir que:

a) Os parâmetros de normalidade da EGG multicanal em voluntários saudáveis em uma população brasileira são semelhantes aos da literatura.

b) Alterações da atividade mioelétrica gástrica por EGG foram encontradas em pacientes com DM1 com ou sem evidência de NAC.

c) A prevalência de disritmias gástricas é maior em pacientes com DM1 com NAC, retardo do esvaziamento gástrico e sintomas de gastroparesia, comparativamente a pacientes com DM1 sem NAC e sem sintomas de gastroparesia e a indivíduos voluntários saudáveis.

d) A porcentagem de normogastria nos períodos basal e pós-prandial parece ser um bom parâmetro, que se associa aos sintomas de pacientes com gastroparesia diabética e NAC. 


\section{Referências}




\section{REFERÊNCIAS}

1. Vinik Al, Erbas T. Recognizing and treating diabetic autonomic neuropathy. Cleve Clin J Med. $2001 ; 68(11): 928-30,932,934-44$.

2. Tesfaye S, Boulton AJM, Dyck PJ, Freeman R, Horowitz M, Kempler P, Lauria G, Malik RA, Spallone V, Vinik A, Bernardi L, Valensi P, and on behalf of the Toronto Diabetic Neuropathy Expert Group. Diabetic neuropathies: update on definitions, diagnostic criteria, estimation of severity, and treatments. Diabetes Care. 2010;33(10):2285-93.

3. Boulton AJ, Malik RA, Arezzo JC, Sosenko JM. Diabetic somatic neuropathies. Diabetes Care. 2004;27(6):1458-86.

4. Vinik Al, Maser RE, Mitchell BD, Freeman R. Diabetic autonomic neuropathy. Diabetes Care. 2003;26(5):1553-79.

5. Verrotti A, Prezioso G, Scattoni R, Chiarelli F. Autonomic neuropathy in diabetes mellitus. Front Endocrinol (Lausanne). 2014;5:205.

6. Sanders KM, Ward SM. Interstitial cells of Cajal: a new perspective on smooth muscle function. J Physiol. 2006;576(3):721-6.

7. Sanders KM, Ward SM, Koh SD. Interstitial cells: regulators of smooth muscle function. Physiol Rev. 2014;94:859-907.

8. Pop-Busui R. Cardiac autonomic neuropathy in diabetes: a clinical perspective. Diabetes Care. 2010;33(2):434-41.

9. Tang ZH, Wang L, Zeng F, Li Z, Yu X, Zhang K, Khou L. Bayesian estimation of cardiovascular autonomic neuropathy diagnostic test based on 
short-term heart rate variability without a gold standard. BMJ Open. 2014;4(9):e005096.

10. Pop-Busui R, Braffett BH, Zinman B, Martin C, White NH, Herman WH, Genuth S, Gubitosi-Klug R, DCCT/EDIC Research Group. Cardiovascular autonomic neuropathy and cardiovascular outcomes in Diabetes Control and Complications Trial/Epidemiology of Diabetes Interventions and Complications (DCCT/EDIC) Study. Diabetes Care. 2017;40(1):94-100.

11. Lefrandt JD, Smit AJ, Zeebregts CJ, Gans RO, Hoogenberg KH. Autonomic dysfunction in diabetes: a consequence of cardiovascular damage. Curr Diabetes Rev. 2010;6(6):348-58.

12. Ewing DJ, Martyn CN, Young RJ, Clarke BF. The value of cardiovascular autonomic function tests: 10 years experience in diabetes. Diabetes Care. 1985;8(5):491-8.

13. Freeman R, Saul JP, Roberts MS, Berger RD, Broadbridge C, Cohen RJ. Spectral analysis of heart rate in diabetic autonomic neuropathy. A comparison with standard tests of autonomic function. Arch Neurol. 1991;48(2):185-90.

14. Risk M, Bril V, Broadbridge C, Cohen A. Heart rate variability measurement in diabetic neuropathy: review of methods. Diabetes Technol Ther. 2001;3(1):63-76.

15. Rolim LSP, Sa JR, Chacra AR, Dib SA. Neuropatia autonômica cardiovascular diabética: fatores de risco, impacto clínico e diagnóstico precoce. Arq Bras Cardiol. 2008;90(4):e24-31.

16. Ziegler D, Laux G, Dannehi K, Spuler M, Muhlen H, Mayer P, Gries FA. Assessment of cardiovascular autonomic function: age-related normal ranges and reproducibility of spectral analysis, vector analysis, an standard 
tests of heart rate variation and blood pressure responses. Diabet Med. 1992;9(2):166-75.

17. Task Force of the European Society of Cardiology and the American Society of Pacing Electrophysiology. Heart rate variability: standards of measurement, physiological interpretation, and clinical use. Circulation. 1996;93(5):1043-65.

18. Muth ER, Stern RM. Significance of autonomic nervous system activity in functional dispepsia. Dig Dis Sci. 2000;45(5):854-63.

19. Camilleri M, Parkman HP, Shafi MA, Abell TL, Gerson L; American College of Gastroenterology. Am J Gastroenterol. 2013;108(1):18-37.

20. Pasricha PJ, Parkman HP. Gastroparesis: definitions and diagnosis. Gastroenterol Clin North Am. 2015;44(1):1-7.

21. Jung HK, Choung RS, Locke GR3rd, Schleck CD, Zinsmeister AR, Szarka LA, Mullan B, Talley NJ. The incidence, prevalence, and outcomes of patients with gastroparesis in Olmsted County, Minnesota, from 1996 to 2006. Gastroenterology. 2009;136(4):1225-33.

22. Choung RS, Locke GR $3^{\text {rd }}$, Schleck CD, Zinsmeister AR, Melton LJ $3^{\text {rd }}$, Talley NJ. Risk of gastroparesis in subjects with type 1 and 2 diabetes in the general population. Am J Gastroenterol. 2012;107(1):82-8.

23. Kofod-Andersen K, Tarnow L. Prevalence of gastroparesis-related symptoms in an unselected cohort of patients with Type 1 diabetes. J Diabetes Complications. 2012;26(2):89-93.

24. Camilleri M, Chedid V, Ford AC, Haruma K, Horowitz M, Jones KL, Low PA, Park SY, Parkman HP, Stanghellini V. Gastroparesis. Nat Rev Primers. 2018;4(1):41. 
25. Bharucha AE, Batey-Schaefer B, Cleary PA, Murray JA, Cowie C, Lorenzi G, Driscoll M, Harth J, Larkin M, Christifi M, Bayless M, Wimmergren N, Herman W, Whitehouse F, Jones K, Kruger D, Martin C, Ziegler G, Zinsmeister AR, Nathan DM, Diabetes Control and Complications TrialEpidemiology of Diabetes Interventions and Complications Research Group. Delayed gastric emptying is associated with early and long-term hyperglycemia in type 1 diabetes melitus. Gastroenterology. 2015;149(2):3309.

26. Grover M, Farrugia G, Lurken MS, Bernard CE, Faussone-Pellegrini MS, Smyrk TC, Parkman HP, Abell TL, Snape WJ, Hasler WL, Unalp-Arida A, Nguyen L, Kock KL, Calles J, Lee L, Tonascia J, Hamilton FA, Pasricha PJ, NIDDK Gastroparesis Clinical Research Consortium. Cellular changes in diabetic and idiopathic gastroparesis. Gastroenterology. 2011;140(5):1575-85.

27. Marathe CS, Rayner CK, Jones KL, Horowitz M. Novel insights into the effects of diabetes on gastric motility. Expert Rev Gastroenterol Hepatol. 2016;10(5):581-93.

28. Farrugia G. Interstitial cells of Cajal in health and disease. Neurogastroenterol Motil. 2008;20(1):54-63.

29. Guo C, Quobatari A, Shangguan Y, Hong S, Wiley JW. Diabetic autonomic neuropathy: evidence for apoptosis in situ in the rat. Neurogastroenterol Motil. 2004;16(3):335-45.

30. Regalia J, Cai F, Helke C. Streptozocin-induced diabetes and the neurochemistry of vagal afferent neurons. Brain Res. 2002;938(1-2):7-14.

31. Aleppo G, Calhoun P, Foster NC, Maahs DM, Shah VN, Miller KM, T1D Exchange Clinic Network. Reported gastroparesis in adults with type 1 diabetes (T1D) from the T1D Exchange clinic registry. J Diabetes Complications. 2017;31(12):1669-73. 
32. Lacy BE, Crowell MD, Mathis C, Bauer D, Heinberg LJ. Gastroparesis: quality of life and health care utilization. J Clin Gastroenterol. 2018;52(1):20-4.

33. Dibaise JK, Patel N, Dueck AC, Crowel MD. The relationship among gastroparetic symptoms, quality of life, and gastric emptying in patients referred for gastric emptying testing. Neurogastroenterol Motil. 2016;28(2):234-42.

34. Revicki DA, Speck RM, Lavoie S, Puelles J, Kuo B, Camilleri M, Almansa C, Parkman HP. The American neurogastroenterology and motility society gastroparesis cardinal symptom index-daily diary (ANMS GCSI-DD): Psycometric evaluation in patients with idiopathic or diabetic gastroparesis. Neurogastroenterol Motil. 2019;31(4):e13553.

35. Revicki DA, Rentz AM, Dubois D, Kahrilas P, Stanghellini V, Talley NJ, Tack J. Development and validation of a patient-assessed gastroparesis symptom severity measure: the Gastroparesis Cardinal Symptom Index. Aliment Pharmacol Ther. 2003;18(1):141-50.

36. Revicki DA, Camilleri M, Kuo B, Szarka LA, McCormack, Parkman HP. Evaluating symptom outcomes in gastroparesis clinical trials: validity and responsiveness of the Gastroparesis Cardinal Symptom Index-Daily Diary (GCSI-DD). Neurogastroenterol Motil. 2012;24(5):456-63.

37. Horowitz M, Harding PE, Chatterton BE, Collins PJ, Shearman DJ. Acute and chronic effects of domperidone on gastric emptying in diabetic autonomic neuropathy. Dig Dis Sci. 1985;30(1):1-9.

38. Silvers D, Kipnes M, Broadstone V, Patterson D, Quigley EM, McCallum R, Leidy NK, Farup C, Liu Y, Joslyn A. Domperidone in the management of symptoms of diabetic gastroparesis: Efficacy, tolerability, and quality of life outcomes in a multicenter controlled trial. Clin Ther. $1998 ; 20(3): 438-53$. 
39. Talley NJ, Verlinden M, Geenen DJ, Hogan RB, Riff D, McCallum RW, Mack RJ. Effects of a motilin receptor agonist (ABT-229) on upper gastrointestinal symptoms in type 1 diabetes mellitus: a randomized, double blind, placebo controlled trial. Gut. 2001;49(3):395-401.

40. Rentz AM, Kahrilas P, Stanghellini V, Tack J, Talley NJ, de la Loge C, Trudeau E, Dubois D, Revicki DA. Development and psychometric evaluation of the patient assessment of upper gastrointestinal symptom severity index (PAGI-SYM) in patients with upper gastrointestinal disorders. Qual Life Res. 2004;13(10):1737-49.

41. Schmier J, Rentz AM, De La Loge C. Development and preliminary psychometric validation of the patient assessment of upper gastrointestinal disorders-symptom severity index (PAGI-SYM) in gastroparesis. Presented at the annual meeting of the International Society for Pharmacoeconomics and Outcomes Research, Antwerp, Belgium, November 2000;3(5):360.

42. Stanghellini V, Tack J. Gastroparesis: separate entity or just a part of dyspepsia? Gut. 2014;63(12):1972-8.

43. Parkman HP, Jones MP. Tests of gastric neuromuscular function. Gastroenterology. 2009;136(5):1526-43.

44. Chinzon D, Navarro-Rodriguez T, Dal-Paz K, Dib RA, Moraes-Filho JPP. Delayed gastric emptying of semi-solid diets in patients with Chagasic Megaesophagus. Medical Express. 2014;1(5):271-4.

45. Szarka LA, Camilleri M, Vella A, Burton D, Baxter K, Simonson J, Zinsmeister AR. A stable isotope breath test with a standard meal for abnormal gastric of solids in the clinic and in research. Clin Gastroenterol Hepatol. 2008;6(6):635-43. 
46. Fidler J, Bharucha AE, Camilleri M, Camp J, Burton D, Grimm R, Riederer SJ, Robb RA, Zinsmeister AR. Application of magnetic resonance imaging to measure fasting and posprandial volumes in humans. Neurogastroenterol Motil. 2009;21(1):42-51.

47. Hasler WL, May KP, Wilson LA, Van Natta M, Parkman HP, Pasricha PJ, Koch KL, Abell TL, McCallum RW, Nguyen LA, Snape WJ, Saroziek I, Clarke JO, Farrugia G, Calles-Escandon J, Grover M, Tonascia J, Lee LA, Miriel L, Hamilton FA, NDDK Gastroparesis Clinical Research Consortium (GpCRC). Relating gastric scintigraphy and symptoms to motility capsule transit and pressure findings in suspected gastroparesis. Neurogastroenterol Motil. 2018;30(2):e13196.

48. Parkman HP, Hasler WL, Fischer RS. American Gastroenterological Association technical review on the diagnosis and treatment of gastroparesis. Gastroenterology. 2004;127(5):1592-622.

49. Rezende Filho J, De Rezende JM, Melo JR. Electrogastrography in patients with Chagas' disease. Dig Dis Sci. 2005;50(10):1882-8.

50. Van Helden DF, Laver DR, Holdsworth J, Imtiaz MS. Generation and propagation of gastric slow waves. Clin Exp Pharmacol Physiol. 2010;37(4):516-24.

51. Publicover NG, Sanders KM. Are relaxation oscillators an appropriate model of gastrointestinal electrical activity? Am J Physiol. 1989;256(1):265-74.

52. O'Grady G, Du P, Paskaranandavadive IN, Angeli TR, Lammers WJ, Asirvatham SJ, Windsor JA, Farrugia G, Pullan AJ, Cheng LK. Rapid highamplitude circumferential slow wave propagation during normal gastric pacemaking and dysrhythmias. Neurogastroenterol Motil. 2012;24(7):e299312. 
53. Huizinga JD, Thuneberg L, Vanderwinden JM, Rumessen JJ. Interstitial cells of Cajal as targets for pharmacological intervention in gastrointestinal motor disorders. Trends Pharmacol Sci. 1997;18(10):393-403.

54. Sarna SK. Gastrointestinal electrical activity: terminology. Gastroenterology. 1975;68:1631-5.

55. Szurszewski JH. The enigmatic electrical slow wave: a mirror on 100 years of research in gut motility. Gastroenterology. 1997;113:1775-87.

56. You CH, Lee KY, Chey WL. Gastric electromyography in normal and abnormal states in humans. In: Chey WL, ed. Functional disorders of the digestive tract. New York: Raven Press; 1983. p.167-73.

57. Daniel EE. The electrical and contractile activity of the pyloric region in dogs and the effects of drugs. Gastroenterology. 1965;49(4):403-18.

58. El-Sharkawy TY, Szurszewski JH. Modulation of canine antral circular smooth muscle by acetylcholine, noradrenaline and pentagastrin. J Physiol (Lond). 1978;279:309-20.

59. Moragan KG, Szurszewski JH. Mechanisms of phasic and tonic actions of pentagastrin on canine antral smooth muscle. J Physiol. 1980;301:229.

60. Torihashi S, Horisawa M, Watanabe Y. c-Kit immunoreactive interstitial cells in the human gastrointestinal tract. J Auton Nerv Syst. 1999;75(1):38-50.

61. O'Grady G, Du P, Cheng LK, Egbuji JU, Lammers WJ, Windsor JA, Pullan AJ. Origin and propagation of human gastric slow-wave activity defined by high-resolution mapping. Am J Physiol Gastrointest Liver Physiol. 2010;299(3):G585-92. 
62. Kito $\mathrm{Y}$, Suzuki H. Electrophysiological properties of gastric pacemaker potentials. J Smooth Muscle Res. 2003;39(5):163-73.

63. Grover M, Bernard CE, Pasricha PJ, Lurken MS, Faussone-Pellegrini MS, McCallum RW, Hamilton FA, Farrugia G, NIDDK Gastroparesis Clinical Research Consortium (GpCRC). Clinical-histological associations in gastroparesis: results from the Gastroparesis Clinical Research Consortium. Neurogastroenterol Motil. 2012;24(6):531-9.

64. Zhu MH, Kim TW, Ro S, Yan W, Ward SM, Koh SD, Sanders KM. A $\mathrm{Ca}(2+)$-activated $\mathrm{Cl}(-)$ conductance in interstitial cells of Cajal linked to slow wave currents and pacemaker activity. J Physiol. 2009;587(20):4905-18.

65. Lammers WJ, Ver Donck L, Stephen B, Smets D, Schuurkes JA. Origin and propagation of the slow wave in the canine stomach: the outlines of a gastric conduction system. Am J Physiol Gastrointest Liver Physiol. 2009;296(6):G1200-10.

66. O'Grady G, Angeli TR, Du P, Lahr C, Lammers WJEP, Windsor JA, Abell TL, Farrugia G, Pullan AJ, Cheng LK. Abnormal initiation and conduction of slow wave activity in gastroparesis defined by high-resolution electrical mapping. Gastroenterology. 2012;143(3):589-98.

67. Yrandi SS, Srinivasan S. Diabetic gastrointestinal motility disorders and the role of enteric nervous system: current status and future directions. Neurogastroenterol Motil. 2014;26(5):611-24.

68. O'Grady G, Abell TL. Gastric arrhythmias in gastroparesis: low- and high-resolution mapping of gastric electrical activity. Gastroenterol Clin North Am. 2015;44(1):169-84. 
69. Du P, O'Grady G, Cheng LK, Pullan AJ. A multiscale model of the electrophysiological basis of the human electrogastrogram. Biophys $\mathrm{J}$. 2010;99(9):2784-92.

70. Leahy A, Besherdas K, Dayman C, Mason I, Epstein O. Abnormalities of the electrogastrogram in functional gastrointestinal disorders. Am J Gastroenterol. 1999;94(4):1023-8.

71. Alvarez WC, Mahoney LJ. Action currents in stomach and intestine. Am J Physiol. 1922;58:476-93.

72. Davis RC, Garafolo L, Gault FP. An exploration of abdominal potentials. J Comp Physiol Psychol. 1957;50(5):519-23.

73. Chen JD, Mc Callum RW, editors. Eletrogastrography: principles and aplications. New York: Raven; 1994. p. 45-73.

74. Yin J, Chen JDZ. Electrogastrography: methodology, validation and applications. J Neurogastroenterol Motil. 2013;19(1):5-17.

75. Lin Z, Chen JDZ, Schirmer BD, McCallum RW. Postprandial response of gastric slow waves: Correlation of serosal recordings with the electrogastrogram. Dig Dis Sci. 2000;45(4):645-51.

76. Parkman HP, Harris AD, Miller MA, Fisher RS. Influence of age, gender, and menstrual cycle on the normal electrogastrogram. Am $\mathrm{J}$ Gastroenterol. 1996;91(1):127-33.

77. Nelsen TS, Kohatsu S. Clinical electrogastrography and its relationship to gastric surgery. Am J Surg. 1968;116(2):215-22.

78. Smout AJPM, van der Schee EJ, Grashuis JL. What is measured in electrogastrography? Dig Dis Sci. 1980;25(3):179-87. 
79. Hamilton JW, Bellahsene BE, Reichelderfer M, Webster JG, Bass P. Human electrogastrograms - Comparison of surface and mucosal recordings. Dig Dis Sci. 1986;31(1):33-9.

80. Angeli TR, Du P, Janssen PW, Cheng LK, O'Grady G. The bioelectrical basis and validity of gastrointestinal extracellular slow wave recordings. J Physiol. 2013;591(18):4567-79.

81. Cooley JW, Tukey JW. An algorithm for machine calculation of complex Fourier series. Math Comput. 1965;19:297-301.

82. van der Schee EJ, Grashuis JL. Running spectral analysis as an aid in the representation and interpretation of electrogastrographic signals. Med Biol Eng Comput. 1987;25:57-62.

83. Chen JDZ, Vandewalle J, Sansen W. Adaptive spectral analysis of cutaneus electrogastric signals using autoregressive moving average modelling. Med Biol Eng Comput. 1990;28(6):531-6.

84. Mintchev MP, Kingma YJ, Bowes KL. Accuracy of cutaneous recordings of gastric electrical activity. Gastroenterology. 1993;104(5):127380.

85. Chen JD, Co E, Liang J, Pan J, Sutphen J, Torres-Pinedo RB, Orr WC. Patterns of gastric myoelectrical activity in human subjects of different ages. Am J Physiol Liver Physiol. 1997;272(5 Pt 1):1022-7.

86. Simonian HP, Panganamamula K, Chen JZ, Fisher RS, Parkman HP. Multichannel electrogastrography (EGG) in symptomatic patients: a single center study. Am J Gastroenterol. 2004;99(3):478-85. 
87. Geldof $H$, van der Schee EJ, van Blankenstein M, Grashuis JL. Electrogastrographic study of gastric myoelectrical activity in patients with unexplained nausea and vomiting. Gut. 1986;27(7):799-808.

88. Calder S, O'Grady G, Cheng LK, Peng Du. A theoretical analysis of electrogastrography (EGG) signatures associated with gastric dysrhythmias. IEEE Trans Biomed Eng. 2017;64(7):1592-601.

89. Krusiec-Świdergoł B, Jonderko K. Multichannel electrogastrography under a magnifying glass--an in-depth study on reproducibility of fed state electrogastrograms. Neurogastroenterol Motil. 2008;20(6):625-34 .

90. Lin X, Chen JZ. Abnormal gastric slow waves in patients with functional dyspepsia assessed by multichannel electrogastrography. Am J Physiol Gastrointest Liver Physiol. 2001;280(6):G1370-5.

91. Sha W, Pasricha PJ, Chen JDZ. Correlations among electrogastrogram, gastric dysmotility, and duodenal dysmotility in patients with functional dyspepsia. J Clin Gastroenterol. 2009;43(8):716-22.

92. Camilleri M, Hasler WL, Parkman HP, Quigley EMM, Soffer E. Measurement of gastrointestinal motility in the Gl laboratory. Gastroenterology. 1998;115(3):747-62.

93. Chen JD, Lin Z, Pan J, McCallum RW. Abnormal gastric myoelectrical activity and delayed gastric emptying in patients with symptoms suggestive of gastroparesis. Dig Dis Sci. 1996;41(8):1538-45.

94. Levanon D, Zhang M, Chen JD. Efficiency and efficacy of the electrogastrogram. Dig Dis Sci. 1998;43(5):1023-30. 
95. Qian LW, Pasricha PJ, Chen JDZ. Origins and patterns of spontaneous and drug-induced canine gastric myoelectrical dysrhythmia. Dig Dis Sci. 2003;48(3):508-15.

96. Koch KL, Bingaman S, Tan L, Stern RM. Visceral perceptions and gastric myoelectrical activity in healthy women and in patients with bulimia nervosa. Neurogastroenterol Motil. 1998;10(1):3-10.

97. Chang CS, Lien HC, Yeh HZ, Poon SK, Tung CF, Chen GH. Effect of cisapride on gastric dysrhythmia and emptying of indigestible solids in type-II diabetic patients. Scand J Gastroenterol. 1998;33(6):600-4.

98. Parkman HP, Hasler WL, Barnett JL, Eaker EY, American Motility Society Clinical GI Motility Testing Task Force. Electrogastrography: A document prepared by the gastric section of the American Motility Society Clinical Gl Motility Testing Task Force. Neurogastroenterol Motil. 2003;15(2):89-102.

99. Koch KL, Stern RM, Stewart WR, Vasey MW. Gastric emptying and gastric myolectrical activity in patients with diabetic gastroparesis: effect of long-term domperidone treatment. Am J Gastroenterol. 1989;84(9):1069-75.

100. Geldof $H$, van der Schee EJ, van Blankenstein M, Smout AJPM, Akkermans LMA. Effects of highly selective vagotomy on gastric myoelectrical activity. An electrogastrographic study. Dig Dis Sci. 1990;35(8):969-75.

101. Abell TL, Camilleri M, Hench VS, Malagelada JR. Gastric electromechanical function and gastric emptying in diabetic gastroparesis. Eur J Gastroenterol Hepatol. 1991;3(2):163-7.

102. Cheng LK. Slow wave conduction patterns in the stomach: from Waller's foundations to current challenges. Acta Physiol (Oxf). 2015;213(2):384-93. 
103. Reddymasu SC, Lin Z, Sarosiel I, Forster J, McCallum RW. Efficacy of gastric electrical stimulation in improving functional vomiting in patients with normal gastric emptying. Dig Dis Sci. 2010;55(4):983-7.

104. Boeckxstaens G, Camilleri M, Sifrim D, Houghton LA, Elsenbruch S, Lindberg G, Azpiroz F, Parkman HP. Fundamentals of Neurogastroenterology:Physiology/Motility- Sensation. Gastroenterology. 2016;S0016-5085(16)00221-3.doi:10.1053/j.gastro.2016.02.030. Online ahead of print.

105. Stoddard CJ, Smallwood RH, Duthie HL. Electrical arrhythmias in the human stomach. Gut. $1981 ; 22(9): 705-12$.

106. Troncon LE, Oliveira RB, Romanello LM, Rosa-e-Silva L, Pinto MC, lazigi N. Abnormal progression of a liquid meal through the stomach and small intestine in patients with Chagas' disease. Dig Dis Sci. 1993;38(8):1511-7.

107. Rezende Filho J. Estudo da atividade mioelétrica gástrica por eletrogastrografia cutânea: eletrogastrograma. Arq Gastroenterol. 1995;32(2):54-65.

108. Quigley EM. Review article: gastric emptying in functional gastrointestinal disorders. Aliment Pharmacol Ther. 2004;20(7):56-60.

109. Censo Demográfico 2010. Características da população e dos domicílios: resultados do universo. Rio de Janeiro: IBGE; 2011.

110. Oba-Kuniyoshi AS, Oliveira JA, Moraes ER, Troncon LEA. Postprandial symptoms in dysmotility-like functional dyspepsia are not related to disturbances of gastric myoelectrical activity. Braz J Med Biol Res. 2004;37(1):47-53. 
111. Abell TL, Camilleri M, Donohoe K, Hasler WL, Lin HC, Maurer AH, McCallum RW, Nowak T, Nusynowitz ML, Parkman HP, Shreve P, Szarka LA, Snape WJ Jr, Ziessman HA, American Neurogastroenterology and Motility Society and the Society of Nuclear Medicine. Consensus recommendations for gastric emptying scintigraphy: a joint report of the American Neurogastroenterology and Motility Society and the Society of Nuclear Medicine. Am J Gastroenterol. 2008;103(3):753-63.

112. Camilleri M. Clinical practice. Diabetic gastroparesis. N Engl J Med. 2007;356(8):820-9.

113. Burbank DP, Webster JG. Reducing skin potential motion artefact by skin abrasion. Med Biol Eng Comput. 1978;16:31-8.

114. Chen J. A computerized data analysis system for electrogastrogram. Comput Biol Med. 1992;22(1-2):45-57.

115. Riezzo G, Russo F, Indrio F. Electrogastrography in adults and children: the strength, pitfalls, and clinical significance of the cutaneous recording of the gastric electrical activity. Biomed Res Int. 2013;282757. https://doi.org/10.1155/2013/282757

116. Mintchev MP, Bowes $\mathrm{KL}$. Extracting quantitative information from digital electrogastrograms. Med Biol Eng Comput. 1996;34(3):244-8.

117. Chen JD, McCallum RW. Clinical applications of electrogastrography. Am J Gastroenterol. 1993;88(9):1324-36.

118. Akoglu H. User's guide to correlation coefficients. Turk J Emerg Med. 2018;18(3):91-3. 
119. Murakami H, Matsumoto H, Ueno D, Kawai A, Ensako T, Kaida Y, Abe T, Hirai T. Current status of multichannel electrogastrography and examples of its use. J Smooth Muscle Res. 2013;49:78-88.

120. Kawagishi T, Nishizawa Y, Emoto M, Maekawa K, Okuno Y, Taniwaki $H$, Inaba M, Ishimura $E$, Morii $H$. Gastric myolectrical activity in patients with diabetes. Role of glucose control and autonomic nerve function. Diabetes Care. $1997 ; 20(5): 848-54$.

121. Nguyen L, Wilson AL, Miriel L, Pasricha PJ, Kuo B, Hasler WL, McCallum RW, Sarosiek I, Koch KL, Snape WJ, Farrugia G, Grover M, Clarke J, Parkman HP, Tonascia J, Hamilton F, Abell TL, NIDDK Gastroparesis Clinical Research Consortium (GpCRC). Autonomic function is gastroparesis and chronic unexplained nausea and vomiting: Relationship with etiology, gastric emptying, and symptom severity. Neurogastroenterol Motil. 2020;32(8):e13810.

122. Abell TL, Bernstein RK, Cutts T, Farrugia G, Forster J, Hasler WL, McCallum RW, Olden KW, Parkman HP, Parrish CR, Pasricha PJ, Prather CM, Soffer EE, Twillman R, Vinik Al. Treatment of gastroparesis: a multidisciplinary clinical review. Neurogastroenterol Motil. 2006;18(4):263-83.

123. Janssen $P$, Harris MS, Jones M, Masaoka T, Farre R, Simrén M, Tack J. The relation between symptom improvement and gastric emptying in the treatment of diabetic and idiopathic gastroparesis. Am J Gastroenterol. 2013;108(9):1382-91.

124. Vjayvargiya P, Camilleri M, Chedid V, Mandawat A, Erwin PJ, Murad $\mathrm{MH}$. Effects of promotility agents on gastric emptying and symptoms: a systematic review and meta-analysis. Gastroenterology. 2019;156(6):1650-60.

125. Tack J, Carbone F. Functional dyspepsia and gastroparesis. Curr Opin Gastroenterol. 2017;33(6):446-54. 
126. Sangnes DA, Softeland E, Bekkelund M, Frey J, Biermann M, Gilja $\mathrm{OH}$, Dimcevski G. Wireless motility capsule compared with scintigraphy in the assessment of diabetic gastroparesis. Neurogastroenterol Motil.2020;32(4):e13771.

127. Park SY, Acosta A, Camilleri M, Burton D, Harmsen WS, Fox J, Szarka LA. Gastric motor dysfunction in patients with functional gastroduodenal symptoms. Am J Gastroenterol. 2017;112(11):1689-99.

128. Kock KL, Hong SP, Xu L. Reproducibility of gastric myolectrical activity and the water load test in patients with dysmotility-like dyspepsia symptoms and in control subjects. J Clin Gastroenterol. 2000;31(2):125-9.

129. Gharibans AA, Coleman TP, Mousa H, Kunkel DC. Spatial patterns from high-resolution electrogastrography correlate with severity of symptoms in patients with functional dyspepsia and gastroparesis. Clin Gastroenterol Hepatol. 2019;17(13):2668-2677.

130. Pasricha PJ, Colvin R, Yates K, Hasler WL, Abell TL, Unalp-Arida A, Nguyen L, Farrugia G, Koch KL, Parkman HP, Snape WJ, Lee L, Tonascia J, Hamilton F. Characteristics of patients with cgronic unexplained nausea and vomiting and normal gastric emptying. Clin Gastroenerol Hepatol. 2011;9(7):567-76.

131. Goucerol G, Ouelaa W, Huet E, Leroi AM, Ducrotte P. Gastric electrical stimulation increases the discomfort threshold to gastric distension. Eur J Gastroenterol Hepatol.2013;25(2):213-7.

132. Angeli TR, Cheng LK, Du P, Wang TH, Bernard CE, Farrugia G, Abell TL, O'Grady G. Loss of interstitial cells of Cajal and patterns of gastric dysrhythmia in patients with chronic unexplained nausea and vomiting. Gastroenterology. 2015;149(1):56-66. 
8 APÊNDICES

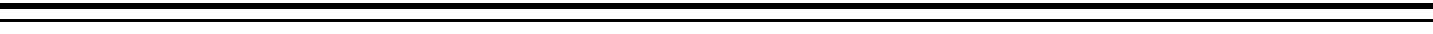




\section{APÊNDICE A - Índice de Sintomas Cardinais de Gastroparesia (GCSI- adaptado)}

Este questionário pergunta sobre a gravidade dos sintomas que você pode ter relacionados a seu problema gastrointestinal. Não há respostas certas ou erradas. Por favor, responda a cada pergunta com a maior precisão possível. Para cada sintoma, por favor, circule o número que melhor descreve quão grave o sintoma tem sido durante as últimas duas semanas: se você ainda não sentiu esse sintoma, circule 0 ; se o sintoma tem sido muito suave, circule 1; se tem sido suave, circule 2; se tem sido moderado, circule 3; se tem sido intenso, circule 4; e se tem sido muito intenso, circule 5. Por favor, certifiquese de responder a cada pergunta.

Por favor, avalie a gravidade dos seguintes sintomas durante as últimas duas semanas:

\begin{tabular}{|c|c|c|c|c|c|c|}
\hline & Nenhum & $\begin{array}{l}\text { Muito } \\
\text { suave }\end{array}$ & Suave & Moderado & Intenso & $\begin{array}{l}\text { Muito } \\
\text { intenso }\end{array}$ \\
\hline $\begin{array}{l}\text { 1. Náusea (sensação } \\
\text { ou vontade de } \\
\text { vomitar) }\end{array}$ & 0 & 1 & 2 & 3 & 4 & 5 \\
\hline $\begin{array}{l}\text { 2. Náusea (como se } \\
\text { quisesse vomitar, } \\
\text { mas nada vem para } \\
\text { cima) }\end{array}$ & 0 & 1 & 2 & 3 & 4 & 5 \\
\hline 3. Vômitos & 0 & 1 & 2 & 3 & 4 & 5 \\
\hline 4. Plenitude gástrica & 0 & 1 & 2 & 3 & 4 & 5 \\
\hline $\begin{array}{l}\text { 5. Não é capaz de } \\
\text { terminar uma refeição } \\
\text { de tamanho normal }\end{array}$ & 0 & 1 & 2 & 3 & 4 & 5 \\
\hline $\begin{array}{l}\text { 6. Sente-se } \\
\text { excessivamente } \\
\text { cheio após as } \\
\text { refeições }\end{array}$ & 0 & 1 & 2 & 3 & 4 & 5 \\
\hline 7. Perda de apetite & 0 & 1 & 2 & 3 & 4 & 5 \\
\hline $\begin{array}{l}\text { 8. Distensão } \\
\text { (sensação de que } \\
\text { precisa abrir a roupa) }\end{array}$ & 0 & 1 & 2 & 3 & 4 & 5 \\
\hline $\begin{array}{l}\text { 9. Estômago e } \\
\text { barriga visivelmente } \\
\text { maiores }\end{array}$ & 0 & 1 & 2 & 3 & 4 & 5 \\
\hline
\end{tabular}


APÊNDICE B-Teste de normalidade incluindo média, desvio padrão e resultado do teste de normalidade de todos os indivíduos incluídos no estudo

\begin{tabular}{lccc}
\hline & Média & DP & Distribuição normal \\
\hline Idade, anos & 40,0 & 11,1 & Sim \\
FD média basal, cpm & 2,8 & 0,2 & $\mathrm{Sim}$ \\
FD média pós-prandial, cpm & 3,0 & 0,3 & $\mathrm{Sim}$ \\
PR & 10,5 & 17,7 & Não \\
FD média total, cpm & 3,0 & 0,3 & Não \\
Normogastria basal, \% & 78,8 & 19,6 & Não \\
Normogastria pós-prandial, \% & 82,7 & 21,6 & Não \\
FD pós-prandial/basal, cpm & 0,2 & 0,3 & Não \\
Cl basal, \% & 14,5 & 5,4 & Sim \\
Cl pós-prandial, \% & 11,2 & 3,5 & Sim \\
Bradigastria basal, \% & 13,1 & 13,1 & Não \\
Bradigastria pós-prandial, \% & 6,6 & 11,7 & Não \\
Taquigastria basal, \% & 7,6 & 13,4 & Não \\
Taquigastria pós-prandial, \% & 10,0 & 20,0 & Não \\
\hline Cl- coeficiente de instabilidade; DP - desvio padrão; FD - frequência dominante; PR- power &
\end{tabular}


APÊNDICE C -Padrões dos gráficos de evolução da frequência dominante (FD) em voluntários saudáveis (grupo controle). Em A, normogastria no período basal (repouso), com FD entre 2,4 cpm e 3,1 cpm. Em B, normogastria no período pós-prandial, com FD entre 2,6 cpm e 3,2 cpm. Houve aumento da variação relativa da potência (período pós-prandial/ período basal), com power ratio $>1$

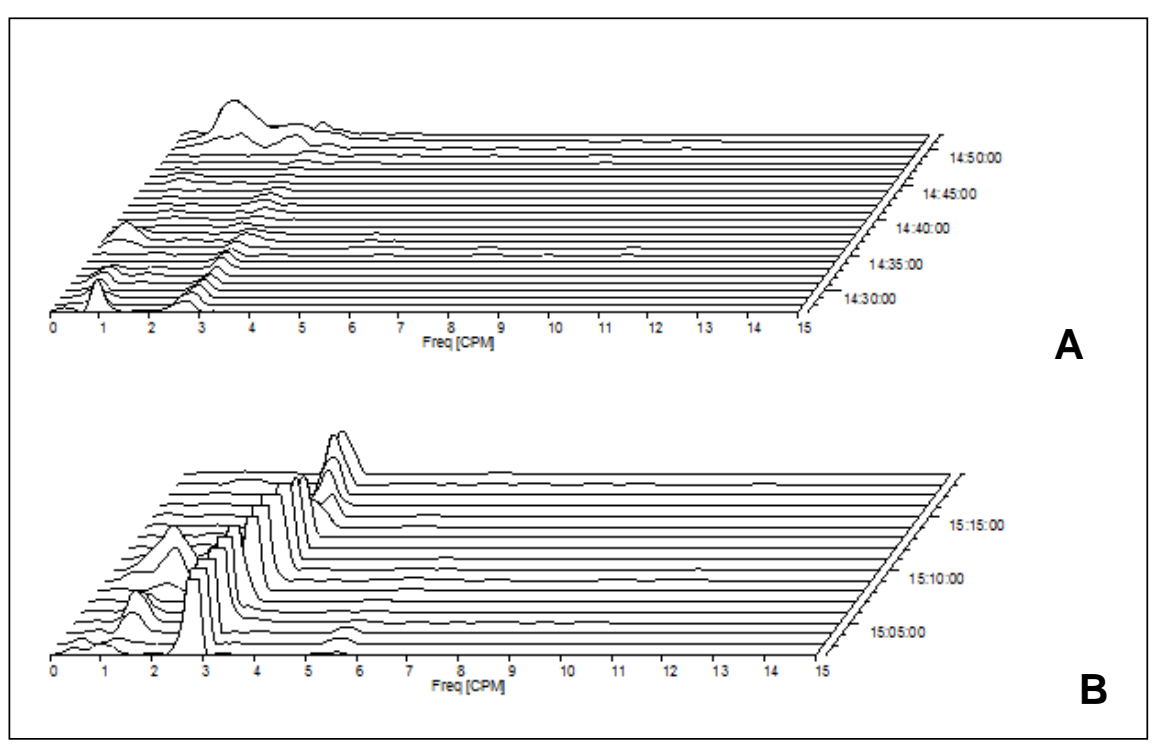


APÊNDICE D - Padrões dos gráficos de evolução da frequência dominante (FD) em pacientes diabéticos sem neuropatia autonômica cardiovascular (grupo 1). Em A, normogastria no período basal (repouso), com FD entre 2,4 cpm e 3,1 cpm. Em B, taquigastria no período pós-prandial, com FD entre $4 \mathrm{cpm}$ e $5 \mathrm{cpm}$. Houve aumento da variação relativa da potência (período pós-prandial/período basal), com power ratio > 1

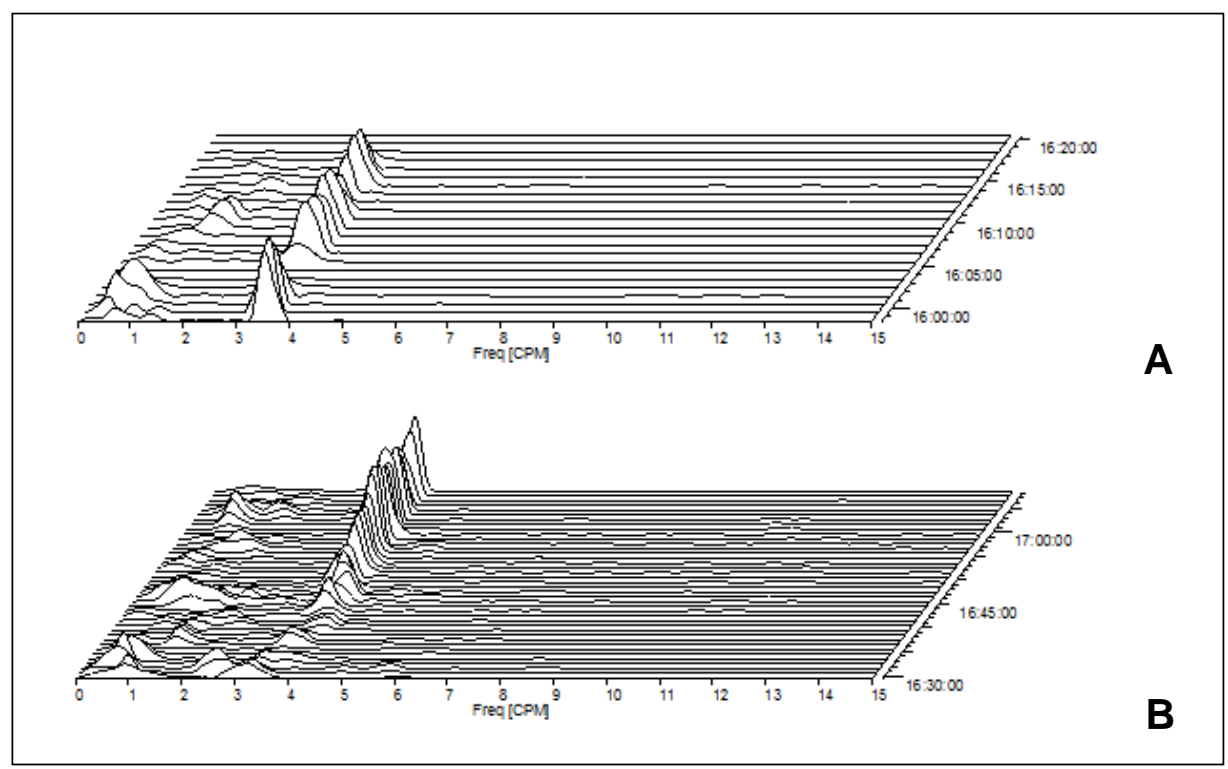


APÊNDICE E - Padrões dos gráficos de evolução da frequência dominante (FD) em pacientes diabéticos com neuropatia autonômica cardiovascular (grupo 2). Em A, normogastria no período basal (repouso), com FD variando entre $2,4 \mathrm{cpm} \mathrm{e} \mathrm{3,1} \mathrm{cpm.} \mathrm{Em} \mathrm{B,} \mathrm{normogastria} \mathrm{no} \mathrm{período}$ pós-prandial, com FD entre 2,6 cpm e 3,2 cpm. Não foi evidenciado aumento da variação relativa da potência (período pós-prandial/ período basal), com power ratio $<1$

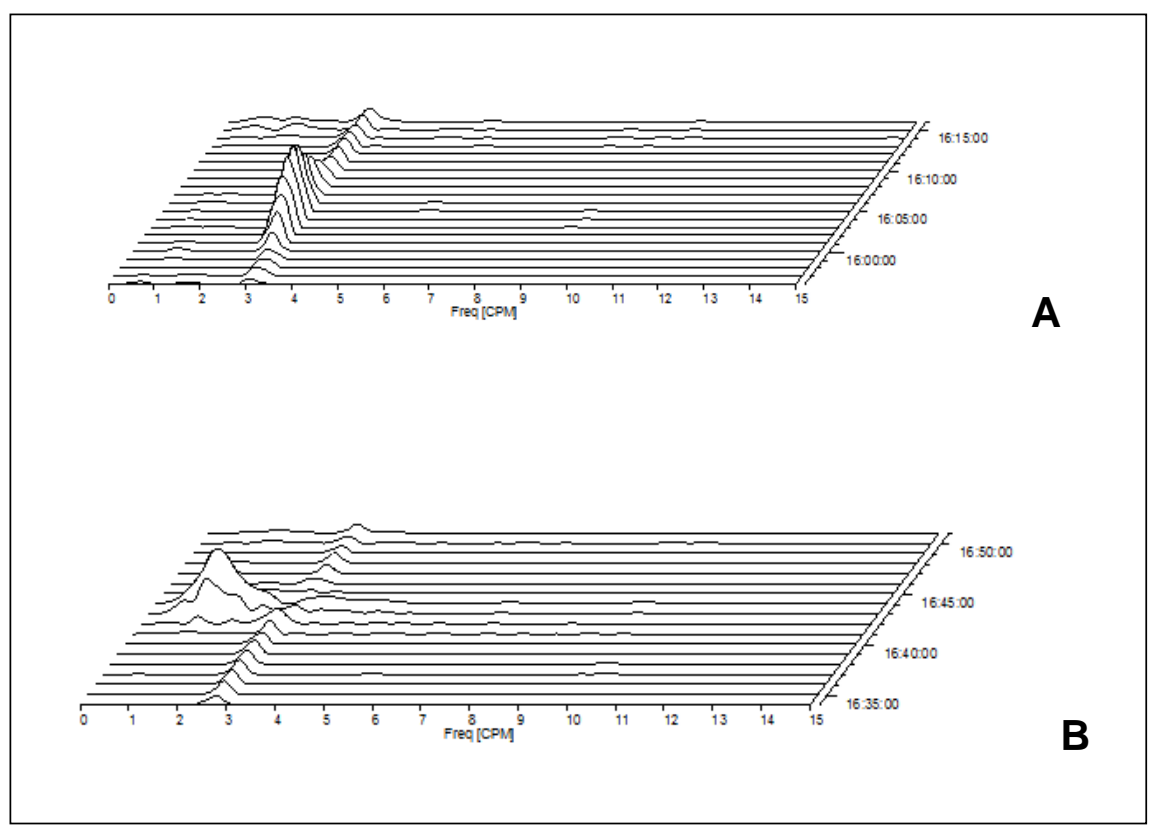


APÊNDICE F - Distribuição de diferentes medidas quantitativas de acordo com os grupos avaliados, incluindo estatísticas de comparações múltiplas entre os grupos
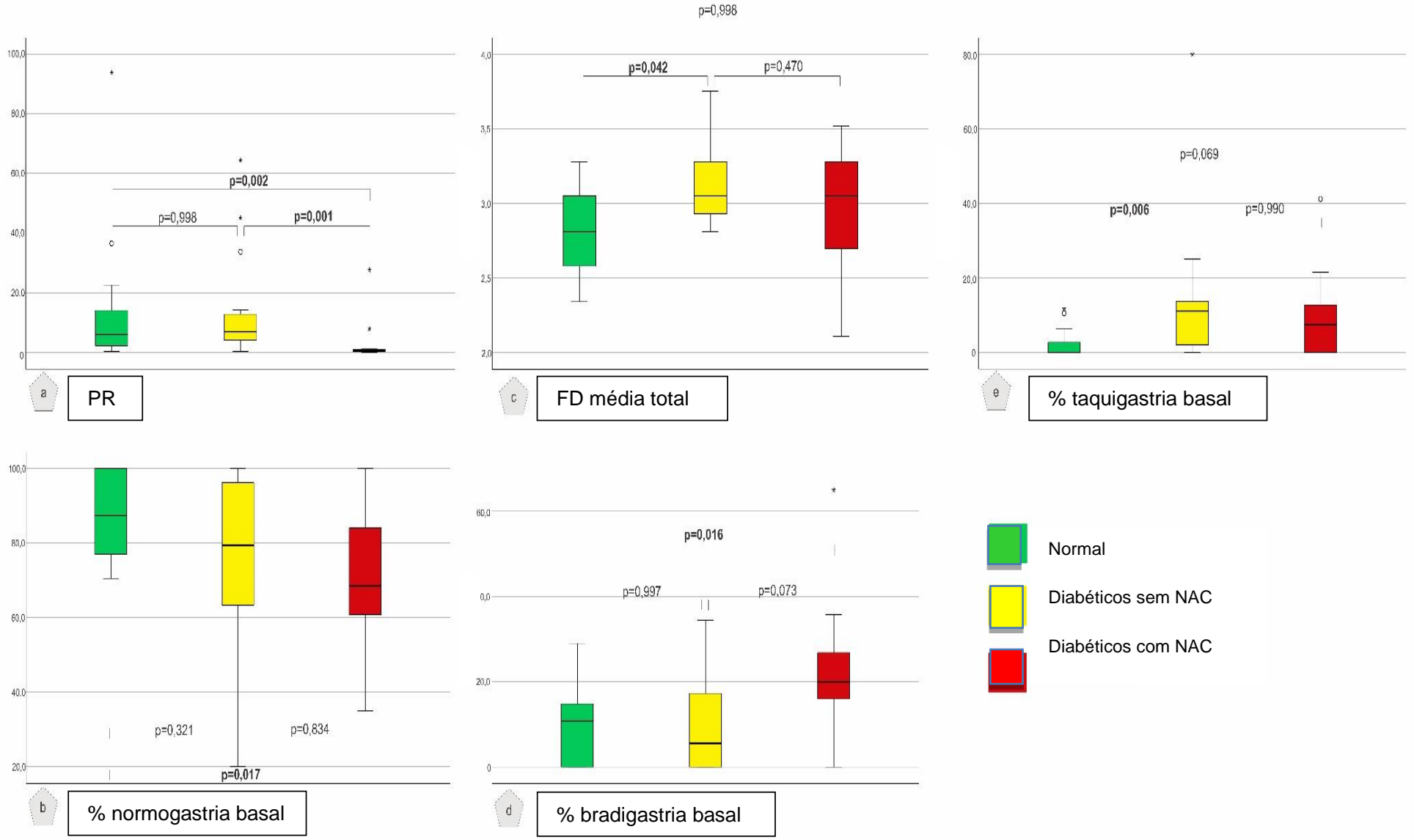

FD - frequência dominante; $P R$ - power ratio.

a $\mathrm{PR}$ - valor de $\mathrm{p}$ (KW de amostras independentes) $<0,001$

c FD média total - valor de $\mathrm{p}$ ( $\mathrm{KW}$ de amostras independentes $)=0,048$

b \% de normogastria basal - valor de $\mathrm{p}$ (KW de amostras independentes) $=0,019$

e \% taquigastria basal - valor de $\mathrm{p}$ (KW de amostras independentes) $=0,005$

d bradigastria basal - valor de $\mathrm{p}$ (KW de amostras independentes $)=0,014$ 
APÊNDICE G - Fluxograma das porcentagens de alterações da eletrogastrografia (EGG) em relação aos grupos avaliados.
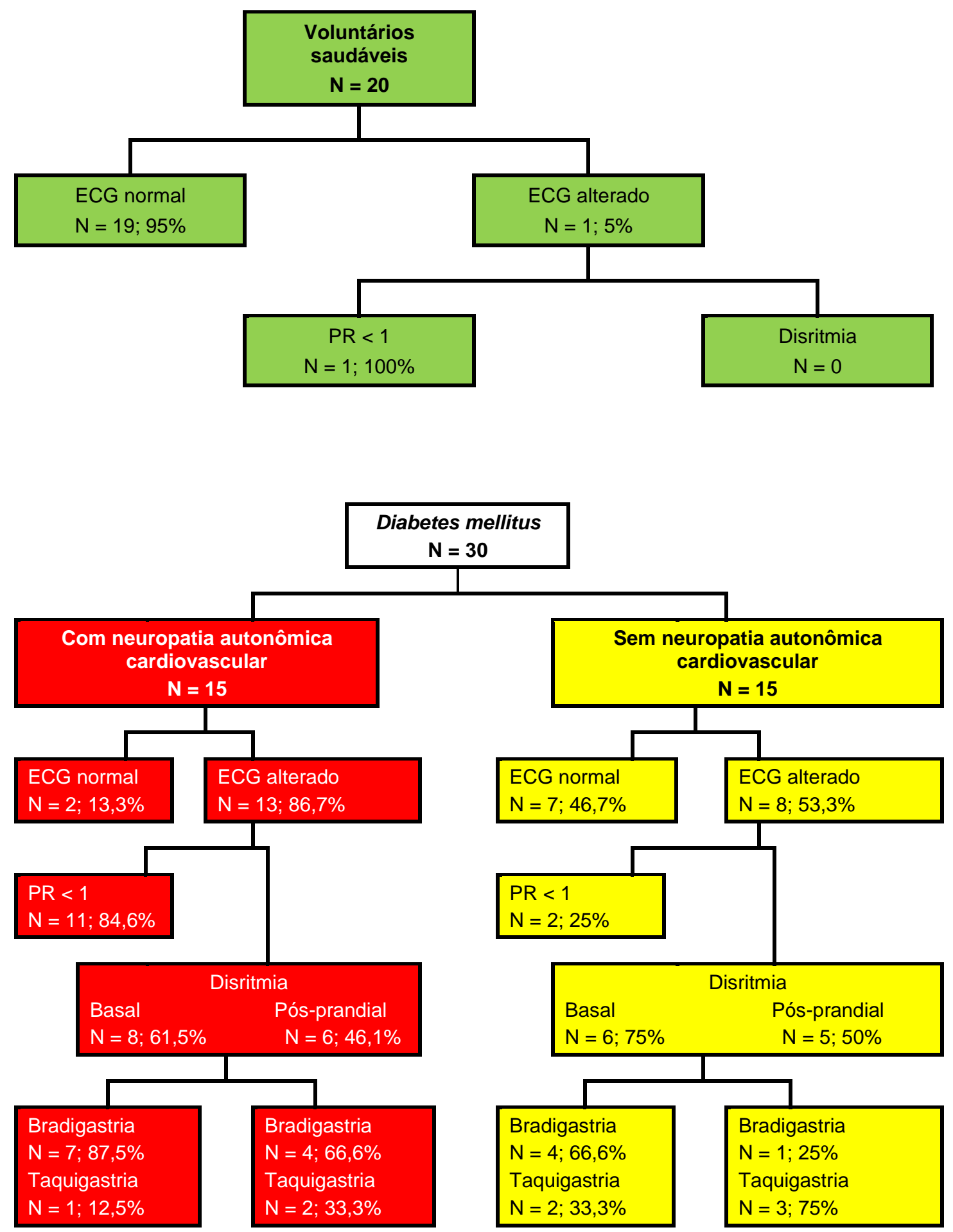